\title{
Fisico-química de las aguas superficiales de la Cuenca del río Rincón, Península de Osa, Costa Rica
}

\author{
Wilson Beita-Sandí1 y Marco Barahona-Palomo² \\ 'Laboratorio de Calidad de Aguas, Centro de Investigación en Contaminación Ambiental, Universidad de Costa Rica, 2060 San José, \\ Costa Rica; wilson.beita@ucr.ac.cr \\ Escuela Centroamericana de Geología, Universidad de Costa Rica, 2060 San José, Costa Rica; mbarahonap@geologia.ucr.ac.cr
}

Recibido 26-II-2010 Corregido 13-IV-2010 Aceptado 30-IV-2010

\begin{abstract}
Hydrochemistry of the surface waters at the Rincon River Basin, Osa Peninsula, Costa Rica. The Rincon River Basin is characterized by steep and rugged topography with outcrops of recent sediments as well as igneous and sedimentary rocks. The area is mostly covered by forest (Tropical Wet Forest) and agricultural land, with some scattered towns. The basin collects water from a total area of $209,8 \mathrm{~km}^{2}$. Water samples were taken along the dry, transition and rainy seasons of 2004 and 2005, through six sampling campaigns and 11 selected sites in the study area. The waters are characterized by an average temperature of $26,8^{\circ} \mathrm{C}$, and an average dissolved oxygen concentration of $7,7 \mathrm{mg} \mathrm{O}_{2} / \mathrm{L}$. The average electrical conductivity (EC) was $161,8 \mu \mathrm{S} / \mathrm{cm}$. They are moderately soft with a range of $\mathrm{pH}$ values between 6,62 and 8,17 and a maximum change of $0,5 \mathrm{pH}$ units. The bicarbonate concentration ranged from $54,3 \mathrm{mg} \mathrm{HCO} / \mathrm{L}$ up to $160,8 \mathrm{mg} \mathrm{HCO} / \mathrm{L}$. They meet the criteria for calcium bicarbonate waters.
\end{abstract}

\section{KEY WORDS}

Aquatic ecosystem, aquatic chemistry, basin, Costa Rica, Osa Peninsula, surface water, water quality, Rincon river.

\section{RESUMEN}

La cuenca del río Rincón tiene una densidad poblacional de alrededor de 30 habitantes por $\mathrm{km}^{2}$, un área total de $209,8 \mathrm{~km}^{2}$ y el río una longitud de 29 km, posee varios tributarios entre ellos el río Riyito, el río Pavón y una gran cantidad de pequeñas quebradas entre las cuales están Aguabuena y Banegas. En ella afloran unidades de roca ígnea y sedimentaria, además de sedimentos recientes. En general, se caracteriza por su topografía abrupta y quebrada. En esta zona se halla un gran número de hábitats tropicales, predominantemente bosque muy húmedoTropical hasta el bosque muy húmedo-Premontano transición a basal. El objetivo principal planteado para este estudio consistió en conocer la calidad química de las aguas superficiales de la cuenca del río Rincón en la Península de Osa. Para ello se seleccionaron 11 sitios de muestreo distribuidos en el área del estudio y en cada uno de ellos se tomaron seis muestras a lo largo de la época seca, la de transición y la lluviosa del año 2004-2005. Las aguas superficiales de la cuenca del río Rincón se caracterizaron por presentar una temperatura promedio de $26,8^{\circ} \mathrm{C}$ y una concentración promedio de oxígeno disuelto de $7,7 \mathrm{mg} \mathrm{O}_{2} / \mathrm{L}$. Las aguas de la cuenca se clasifican como aguas moderadamente suaves. El ámbito de valores de $\mathrm{pH}$ medidos en la cuenca estuvo entre 6,62 y 8,17, con una variación promedio de 0,5 unidades. La conductividad promedio en la cuenca fue $161,8 \mu \mathrm{S} / \mathrm{cm}$. El ámbito de concentraciones de bicarbonato fue de $54,3 \mathrm{mg} \mathrm{HCO}_{3} / \mathrm{L}$ a $160,8 \mathrm{mg} \mathrm{HCO} / \mathrm{L}$. Según la clasificación de Piper las aguas superficiales de la cuenca del río Rincón son bicarbonatadas cálcicas. La calidad del agua superficial de la cuenca del río Rincón es apta para la preservación y la conservación de la vida acuática.

\section{PALABRAS CLAVE}

Ecosistemas acuáticos, química del agua, cuenca, Costa Rica, Península de Osa, agua superficial, calidad del agua, Río Rincón. 
Los ríos son sistemas dinámicos que modifican su naturaleza a lo largo de su curso, debido a cambios en las condiciones físicas tales como las pendientes y la geología de su lecho (Bellos \& Sawidis 2005). La química del agua superficial en cualquier punto refleja importantes influencias: litológicas, atmosféricas, climáticas y antropogénicas, por lo que es fundamental poder identificar y cuantificar estas influencias.

En el estudio de ecosistemas naturales, muchas variables cambian simultáneamente con el tiempo y la ubicación con muy pocas oportunidades de controlarlas. En la medida en que se puedan medir tantas variables como sea posible que describan el sistema, es posible que se pueda entender sus interacciones y establecer la sostenibilidad ambiental (Jonnalagada \& Mhere 2001).

En la evaluación de la calidad del agua de un río se comparan los valores medidos de la concentración de un parámetro fisicoquímico o biológico, con los estándares de calidad establecidos en algún instrumento legal, y definidas de acuerdo con criterios de uso del agua (Kowalkowski et al. 2006).

Este estudio se desarrolló en la Península de Osa que se ubica en la provincia de Puntarenas, en el Pacífico Sur de Costa Rica. Con una altitud máxima de $782 \mathrm{msnm}$, se caracteriza por tener una topografía abrupta y quebrada, y ser una de las regiones geológicas más antiguas de Costa Rica (78-44 Mill. años) (Berrange 1989). En ella afloran unidades de roca ígnea y sedimentaria, además de sedimentos recientes (Barrios et al. 1998). Las rocas ígneas extrusivas fueron formadas en un ambiente volcánico submarino; las rocas sedimentarias presentes son de composición silícea o carbonatada. Todas estas formaciones geológicas han sido afectadas por el tectonismo de la región, lo que ha causado fracturamiento y callamiento (Denyer \& Kussmaul 2000). Esta condición, es ideal para la formación de acuíferos en formaciones rocosas que de otra manera serían malas almacenadoras y conductoras de agua.

Cerca de la costa y en los valles aluviales, se encuentran depósitos granulares recientes los cuales en general se comportan como acuíferos. La interacción agua-roca dentro de los acuíferos altera las características químicas del agua subterránea, lo cual se refleja en la conductividad, la dureza y la concentración de diferentes iones mayores.

En la Península de Osa se halla un gran número de hábitats tropicales, con zonas de vida según Holdridge (1982) desde el bosque muy húmedo-Tropical (50\% de la península), donde se encuentra la mayor parte del área protegida, hasta el bosque muy húmedo-Premontano transición a basal que cubre el $20 \%$ de la península. Estos bosques son las últimas formaciones muy húmedas que aún existen en el pacífico Centroamericano. Estudios recientes (Rosero et al. 2002) muestran la complejidad de estos bosques, que presentan afinidades florísticas tanto con bosques de Mesoamérica como de Sudamérica ocupan el tercer lugar en riqueza de especies en comparación con 89 sitios Neotropicales analizados.

Dentro de la cuenca del río Rincón se encuentra únicamente la estación Rincón de Osa, estación No. 10039 del Instituto Meteorológico Nacional (IMN), la cual tiene registros de precipitación para los períodos 1942-1954, 1964-1973, 1998-2004. La precipitación promedio anual en la zona varió entre $3500 \mathrm{~mm}$ y $5500 \mathrm{~mm}$ durante estos períodos, con las zonas más lluviosas en la zona montañosa central y menos lluviosa hacia las zonas bajas próximas al Golfo Dulce.

Según Barrantes et al. (1985), la temperatura promedio anual varía entre $22,5^{\circ} \mathrm{C}$ y $30,0^{\circ} \mathrm{C}$, con máximas que varían desde los $25,0^{\circ} \mathrm{C}$ hasta los $32,5^{\circ} \mathrm{C}$; y mínimas entre $20,0^{\circ} \mathrm{C}$ y $22,5^{\circ} \mathrm{C}$. En la cuenca del río Rincón el clima que predomina es de tipo muy húmedo, muy caliente, con una estación seca corta; en la cumbre del cerro Rincón, el clima es muy húmedo, caliente, con una estación seca corta (Herrera 1985).

La actividad de extracción de oro de placeres, que durante muchas décadas se dio en la Península de Osa, tanto de manera artesanal como de manera industrial (Vargas 1989), provocó un impacto sobre la calidad del aguas y los bosques cuya magnitud no ha sido sistemáticamente evaluada.

En un estudio anterior realizado por Umaña (1998) se caracterizó, de manera regional mediantes algunos parámetros fisicoquímicos y biológicos, el agua superficial de algunos ríos que desembocan en el Golfo Dulce, incluidos dos puntos en el río Rincón. El estudio de la calidad del agua de esta zona es de interés, debido al potencial turístico que ofrece la región y a los procesos de minería y de deforestación que ha experimentado (Herrera 1985). La densidad poblacional en esta cuenca es de alrededor de 30 habitantes por $\mathrm{km}^{2}$ y la mayoría utiliza el agua para consumo humano, ganadería y parte para agricultura.

En las últimas décadas Costa Rica ha experimentado un deterioro en la calidad de sus ríos, las principales causas de este detrimento coinciden con un aumento de la densidad poblacional asociado a la ausencia de políticas de planificación urbana y a la falta de alcantarillado y de tratamiento de aguas residuales. El impacto que las actividades de origen antrópico han tenido en la Península de Osa parece ser diferente al ocurrido en el gran área metropolitana por lo que la información que se genere puede ser usada como referencia para compararla contra la de otros ríos de Costa Rica y al mismo tiempo para establecer 
metas de recuperación y de conservación de cuerpos de agua superficiales. En el presente trabajo se pretende caracterizar la calidad de las aguas superficiales de la cuenca del río Rincón en la Península de Osa, mediante parámetros fisicoquímicos.

\section{METODOLOGÍA}

\section{El área de estudio}

La cuenca del río Rincón se encuentra en los cantones de Osa y Golfito de la provincia de Puntarenas; entre las coordenadas geográficas $8^{\circ} 29^{\prime} 53^{\prime \prime} \mathrm{N}-8^{\circ} 44^{\prime} 10^{\prime \prime} \mathrm{N}$, y $83^{\circ} 27^{\prime} 47^{\prime \prime} \mathrm{W}-83^{\circ} 35^{\prime} 55^{\prime \prime} \mathrm{W}$. Tiene un área total de $209,8 \mathrm{~km}^{2}$ (Rosero et al. 2002). El río Rincón tiene una longitud de $29 \mathrm{~km}$, posee varios tributarios entre ellos el río Riyito, el río Pavón y una gran cantidad de pequeñas quebradas entre las cuales están las quebradas Aguabuena y Banegas. Su punto más alto es el cerro Rincón $(780 \mathrm{msnm})$ y el más bajo, el nivel del mar. Al norte limita con los cerros Chocuaco y la fila Ganado y al este con el Golfo Dulce (en la desembocadura del río Rincón).

\section{Estaciones de muestreo}

La cuenca del río Rincón se dividió en 11 sub-cuencas y en cada una de ellas se estableció una estación de muestreo. Entre el 14 de diciembre del 2004 y el 14 de septiembre del 2005 se recolectaron y analizaron 60 muestras de agua a los largo de las seis estaciones de muestreo. En cada estación se realizaron mediciones de temperatura y de la concentración del oxígeno disuelto y se tomó suficiente cantidad de muestra para ser transportada al laboratorio bajo condiciones controladas de temperatura, y una vez en el laboratorio, se almacenaron en un cuarto frío a $4^{\circ} \mathrm{C}$.

\section{Metodología analítica}

Las muestras de agua fueron analizadas en el Laboratorio de Calidad de Aguas del Centro de Investigación en Contaminación Ambiental con metodologías estandarizadas (Eaton et al. 1998) y acreditadas bajo los lineamientos de la norma INTE-ISO/IEC 17025:2000. A cada una de las muestras de agua se le realizaron los siguientes análisis: Alcalinidad Parcial y Total (Método 2320 B), Calcio (Método $3500 \mathrm{Ca}$ ), Cloruros (Método $4110 \mathrm{C}$ ), Conductividad (Método 2510 B), Dureza Total (Método 2340 C), Fósforo Total (Método 4500-P C), Magnesio (Método 3500-Mg B), Nitratos (Método 4110 C), pH (Método 4500-H+ B), Potasio (Método 3500-K B), Sodio (Método 3500-Na B), Sulfatos (Método $4110 \mathrm{C}$ ).

\section{Análisis de los datos}

Se verificó que los datos tuvieran una distribución normal. Seguidamente, se realizó un análisis de varianza (ANDEVA) de un factor. El ANDEVA ofrece una prueba para determinar si se acepta o rechaza una hipótesis nula, bajo la suposición de que los errores están normalmente distribuidos. En primer lugar, con la información obtenida se quiso responder dos preguntas fundamentales, que permitieran el análisis y comparación de estos datos con respecto a la calidad del agua para su uso en la conservación y preservación de la vida acuática. Las preguntas fueron: ¿Existió diferencia estadísticamente significativa al 95\% de confianza entre las mediciones realizadas en una misma estación de muestreo? ¿Existió diferencia estadísticamente significativa al 95\% de confianza entre las mediciones realizadas, de un mismo parámetro, en las distintas estaciones de muestreo?

\section{RESULTADOS}

Los resultados de los análisis fisicoquímicos medidos durante el período de estudio, se muestran en el Cuadro 1.

Las aguas superficiales de la cuenca del río Rincón están caracterizadas por una temperatura promedio de $26,8^{\circ} \mathrm{C}\left(22,0^{\circ} \mathrm{C}\right.$ a $\left.32,5^{\circ} \mathrm{C}\right)$. Los niveles de OD en la Laguna Chocuaco ( $\mathrm{CHO}$ ) se encontraron cercanos a cero, en el resto de las estaciones el valor promedio fue $7,7 \mathrm{mg} \mathrm{O}_{2} / \mathrm{L}$ suficiente para mantener y conservar la vida acuática de las especies más sensibles. La época lluviosa se caracterizó por presentar los valores más bajos de dureza total, el valor mínimo fue $42,4 \mathrm{mg} \mathrm{CaCO} / \mathrm{L}$ y el máximo 122,8 $\mathrm{mg} \mathrm{CaCO}_{3} / \mathrm{L}$. Las aguas de la cuenca se clasificaron como aguas moderadamente suaves.

El ámbito de valores de $\mathrm{pH}$ medidos en la cuenca se encuentra entre 6,62 (abr-05 en CHO) y 8,17 (feb-05 en RNM), con una variación promedio y máxima de 0,5 y 1 unidades de $\mathrm{pH}$ respectivamente. Los valores de $\mathrm{pH}$ medidos en las aguas de la cuenca del río Rincón, durante el periodo de estudio, se encontraron dentro del ámbito recomendado en las diferentes normativas ambientales de 6,5 a 8,5.

Las concentraciones de cloruros en la mayoría de las estaciones se encontraron por debajo del límite de cuantificación del método de análisis que se empleó en su determinación, que es de $0,63 \mathrm{mg} \mathrm{Cl}-/ \mathrm{L}$. El ámbito de concentraciones de calcio fue de $8,93 \mathrm{mg} \mathrm{Ca}_{2}{ }^{+} / \mathrm{L}$ a $34.5 \mathrm{mg}$ $\mathrm{Ca}_{2}{ }^{+} / \mathrm{L}$. La parte alta de la cuenca presentó los valores más altos (RNA), mientras que en la laguna Chocuaco ( $\mathrm{CHO}$ ) y los afluentes del río Riyito (QSN, QBN) se midieron las menores concentraciones. El ámbito de concentraciones de magnesio fue de $3,92 \mathrm{mg} \mathrm{Mg}_{2}{ }^{+} / \mathrm{L}$ a $10,87 \mathrm{mg} \mathrm{Mg}_{2}{ }^{+} / \mathrm{L}$, la 


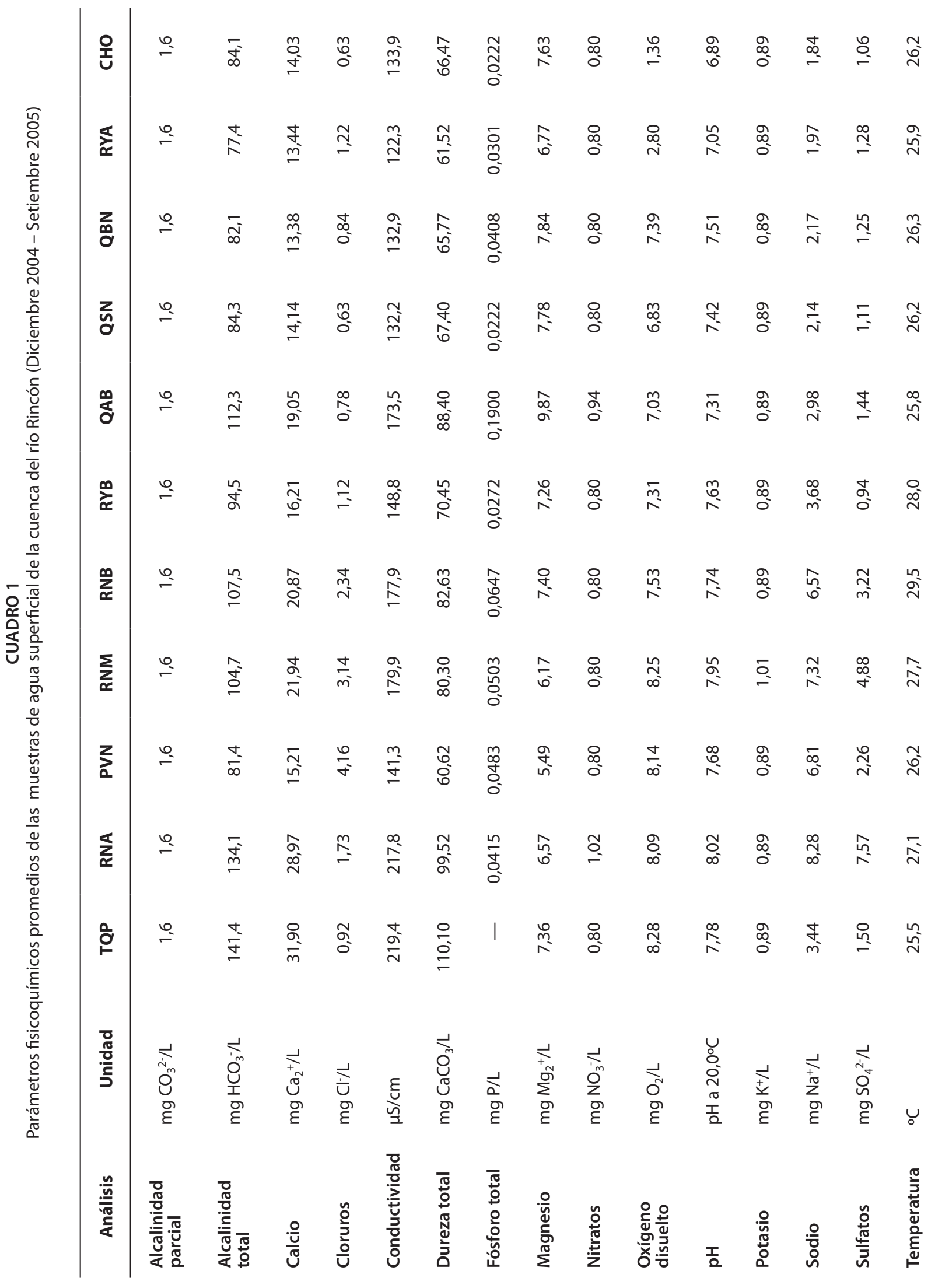


concentración promedio fue de $7,3 \mathrm{mg} \mathrm{Mg}_{2}{ }^{+} / \mathrm{L}$ con una desviación estándar de 1,6mg $\mathrm{Mg}_{2}{ }^{+} / \mathrm{L}$. La estación de muestro localizada en la parte alta del quebrada Aguabuena (QAB) mostró la mayor concentración promedio 9,87mg $\mathrm{Mg}_{2}{ }^{+} / \mathrm{L}$.

Por otro lado, la conductividad promedio medida en las

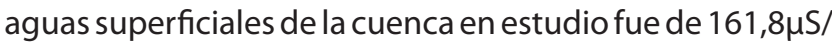
$\mathrm{cm}$, con un ámbito desde $92,7 \mu \mathrm{S} / \mathrm{cm}$ hasta $249,6 \mu \mathrm{S} / \mathrm{cm}$. La conductividad promedio más baja $(122,3 \mu \mathrm{S} / \mathrm{cm})$ corresponde a las mediciones realizadas en RYA, ligeramente por debajo del CHO, QBN y QSN. Mientras que el promedio de mediciones más altas fueron las de TQP; con un promedio de $219,4 \mu \mathrm{S} / \mathrm{cm}$.

La mayoría de las estaciones no presentaron valores de concentración cuantificables de sulfatos (L.C. $=0,67 \mathrm{mg}$ $\left.\mathrm{SO}_{4}{ }^{2-} / \mathrm{L}\right)$, el ámbito estuvo entre $0.67 \mathrm{mg} \mathrm{SO}_{4}{ }^{2-} / \mathrm{L}$ y $9,59 \mathrm{mg}-$ $\mathrm{SO}_{4}{ }^{2-} / \mathrm{L}$, ni potasio $\left(<0,89 \mathrm{mg} \mathrm{K} \mathrm{K}^{+} / \mathrm{L}\right)$; el ámbito de concentraciones de sodio fue $0,3 \mathrm{mg} \mathrm{Na} / / \mathrm{L}$ a $9,54 \mathrm{mg} \mathrm{Na}^{+} / \mathrm{L}$.

El ámbito de concentraciones de bicarbonato fue de 54,3mg $\mathrm{HCO}_{3}{ }^{-} / \mathrm{L}$ a $160,8 \mathrm{mg} \mathrm{HCO}_{3}{ }^{-} / \mathrm{L}$. La estación de muestro localizada en la parte alta del río Rincón (RNA) mostró la mayor concentración promedio 134,1 $\mathrm{mg} \mathrm{HCO}_{3}^{-} / \mathrm{L}$.

No se determinaron concentraciones cuantificables de nitratos durante el período de estudio, 2004-2005, siempre estuvieron por debajo de $0,80 \mathrm{mg} \mathrm{NO}_{3}^{-} / \mathrm{L}$, y aunque no es posible establecer una clasificación completa de la condición trófica si se puede concluir que las aguas de la cuenca del río Rincón distan mucho de una condición eutrófica $(0,035 \mathrm{mg}$ P/L). Y lo más importante, las ligeras variaciones presentadas no fueron estadísticamente significativas tanto entre los resultados estacionales ( $p>0,05$ y $6 \mathrm{gl}$ ) como temporales ( $\mathrm{p}>0,05$ y $10 \mathrm{gl}$ ).

En general, se puede considerar que las actividades humanas que se dan en la cuenca no han tenido un impacto negativo sobre la calidad del agua y más bien las concentraciones de los principales parámetros fisicoquímicos medidos, representan condiciones geogénicas de la cuenca.

Además, mediante el análisis geoquímico de las aguas superficiales de la cuenca del río Rincón se determinó que los iones predominantes son el bicarbonato y el calcio (bicarbonatadas cálcicas según la clasificación de Piper).

\section{DISCUSIÓN}

\section{Clasificación hidrogeoquímica}

Con el propósito de obtener una clasificación geoquímica de las aguas superficiales de la cuenca del río Rincón y poder relacionarla con la geología e hidrología de la zona, se elaboraron diagramas de Piper. Se consideraron los cationes principales: calcio, magnesio, sodio y potasio y los aniones: cloruro, sulfato y bicarbonato. Debido a que las concentraciones de nitrato se encontraban por debajo del límite de cuantificación del método de análisis empleado en el Laboratorio de Calidad de Aguas, no se tomó en consideración. Una vez que se ha construido el diagrama, se nombra el agua por el anión y catión que se encuentren de manera mayoritaria. En la Fig. 1 se muestra el diagrama de Piper que contiene las once estaciones de muestreo seleccionadas en la cuenca del río Rincón.

En el triangulo inferior izquierdo (Fig. 1) se muestran los valores de concentración (en porcentaje) de los cationes y en el derecho los aniones. Del diagrama se concluye que el catión predominante corresponde a calcio, seguido de magnesio; mientras que en los aniones un valor cercano al $100 \%$ es de bicarbonato, por lo que con base en esta clasificación las aguas superficiales de la cuenca del río Rincón son del tipo bicarbonatada cálcica.

La clara relación que existe en las aguas superficiales de la zona en estudio, entre el bicarbonato y el calcio, se observa en la figura 2, es claro notar que hay una dependencia lineal entre ambos iones, no así entre el bicarbonato y el sodio por ejemplo (Fig. 3).

\section{Caracterización química}

La clasificación de la calidad del agua de un río se basa generalmente en la comparación de los valores medidos

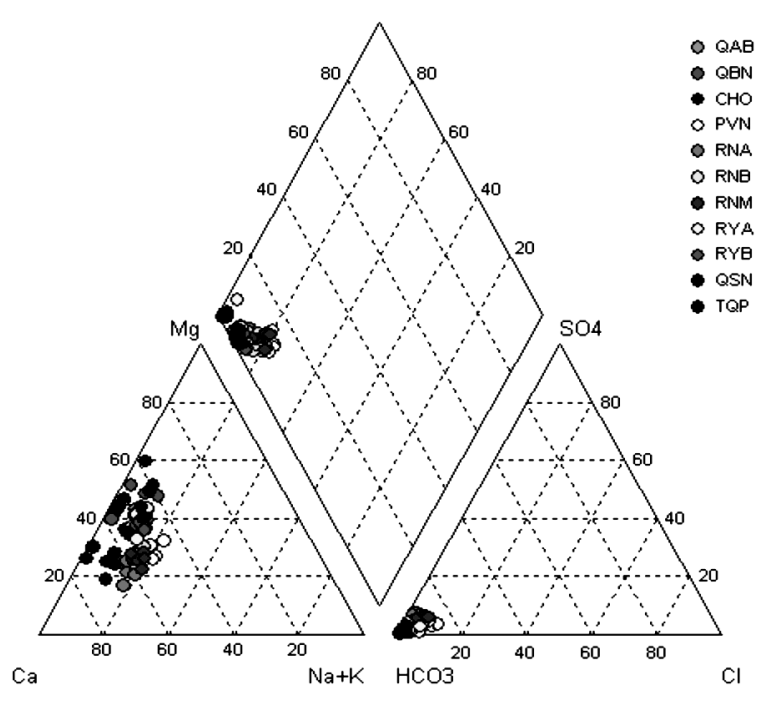

FIG. 1. Diagrama de Piper de las aguas superficiales de la cuenca del Río Rincón en la Península de Osa.

Vea ésta figura a color en la versión digital (www.uned.ac.cr/investigacio/ publicaciones/cuaderno1/). 


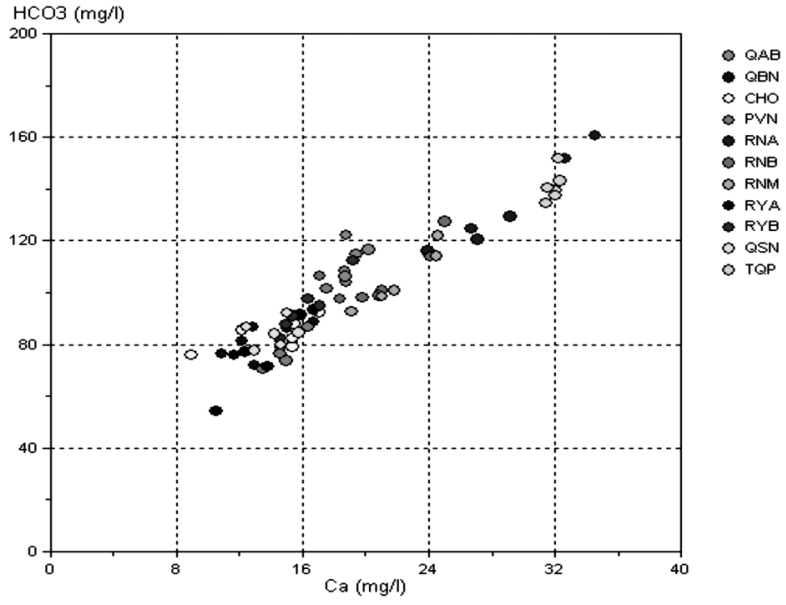

FIG. 2. Relación entre los iones calcio y bicarbonato en las aguas superficiales de la cuenca del Río Rincón.

Vea ésta figura a color en la versión digital (www.uned.ac.cr/investigacio/ publicaciones/cuaderno1/).

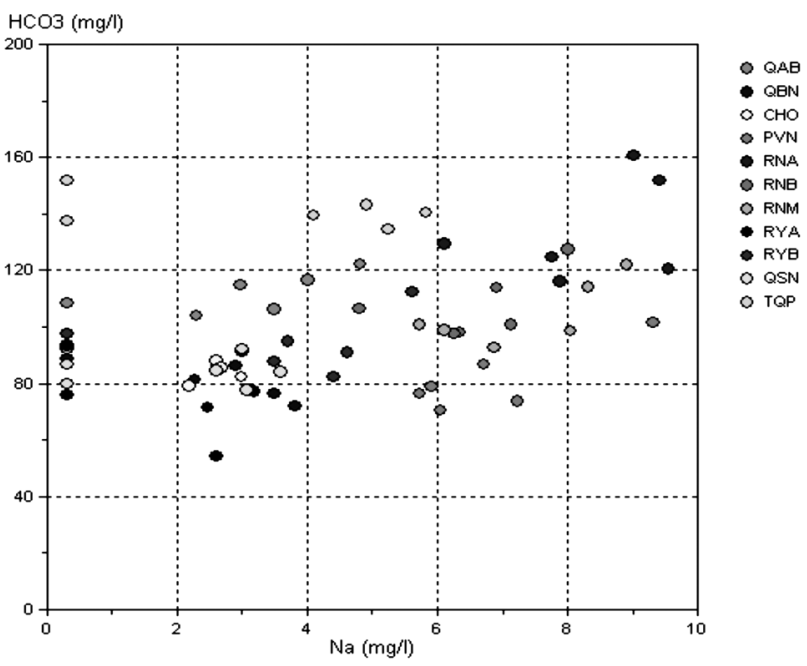

FIG. 3. Relación entre los iones sodio y bicarbonato en las aguas superficiales de la cuenca del Río Rincón.

Vea ésta figura a color en la versión digital (www.uned.ac.cr/investigacio/ publicaciones/cuaderno1/).

de la concentración de un parámetro específico con los valores límites definidos bajo un instrumento legal apropiado. Los estándares de calidad para un río, se basan en los usos que se le dan al cuerpo de agua.

\section{Dureza total}

Las fluctuaciones en la dureza de las aguas superficiales en la cuenca del río Rincón y sus tributarios se muestran en la Fig. 4. La estación RNA estuvo caracterizada por valores de concentración altos de dureza $(122,8 \mathrm{mg}$ $\mathrm{CaCO}_{3} / \mathrm{L}$ ) y al igual que la mayoría de las otras estaciones, estos valores se presentaron en la época seca (febrero); no obstante, presentó la mayor variabilidad $(s=14,9 \mathrm{mg}$ $\mathrm{CaCO}_{3} / \mathrm{L}$ ). Las aguas captadas en el tanque principal (estación TQP) también estuvieron caracterizadas por valores altos, no obstante presentaron una baja variabilidad $(\mathrm{s}=6,1 \mathrm{mg} \mathrm{CaCO} / \mathrm{L})$.

La época lluviosa se caracterizó por presentar los valores más bajos de dureza, RYA presentó el mínimo $(42,4 \mathrm{ppm}$ $\left.\mathrm{CaCO}_{3}\right)$, aunque como se observa en la figura 4 algunos pequeños tributarios del río Riyito (RYA) mostraron la misma tendencia. Los valores de la dureza total durante el periodo de estudio en la cuenca del río Rincón presentaron un mínimo de $42,4 \mathrm{mg} \mathrm{CaCO}_{3} / \mathrm{L}$ y un valor máximo de $122,8 \mathrm{mg} \mathrm{CaCO}_{3} / \mathrm{L}$. Las aguas de la cuenca se clasifican como aguas moderadamente suaves.

No hubo diferencia estadísticamente significativa entre los resultados de las estaciones de muestreo $(p>0.05$ y $6 \mathrm{gl})$, pero sí hubo diferencia entre los resultados temporales $(p<0,05$ y 10 g.l).

\section{Potencial de hidrógeno $(\mathrm{pH})$}

El pH es controlado por el balance entre el dióxido de carbono, los iones bicarbonato y carbonato, así como los ácidos húmicos y fúlvicos. La mayoría de las aguas naturales tienen un pH en el ámbito de 6,5 a 8,0 y es controlado principalmente por el sistema carbonato - bicarbonato (Stumm \& Morgan 1996). Sin embargo, existen aguas húmicas ácidas, cuyo ámbito de pH de 5,0 a 6,0 y es controlado por la concentración natural de materia orgánica en lugar del sistema de amortiguamiento de carbonatobicarbonato. La mayoría de las aguas tienen cierta capacidad de amortiguar (o resistir) los cambios de pH. Esta capacidad es a menudo medida en términos de la alcalinidad del sistema. En los ríos esta capacidad se debe sobre todo, a la presencia de iones bicarbonato $\left(\mathrm{HCO}_{3}{ }^{-}\right)$, aportados al sistema por la disolución de rocas y suelos (Drever 1988, Stumm \& Morgan 1996).

Cuando la capacidad de amortiguamiento es muy baja pueden presentarse cambios en el ámbito de $\mathrm{pH}$ muy importantes. Por ejemplo, en un cuerpo de agua donde haya una alta productividad primaria durante el día, el fitoplancton puede consumir el $\mathrm{CO}_{2}$ disuelto a una tasa mayor con la que se reemplaza desde la atmósfera, lo que provoca un desequilibrio entre las concentraciones de $\mathrm{CO}_{2}$ y $\mathrm{HCO}_{3}{ }^{-}$, incrementando el $\mathrm{pH}$, como se muestra en las ecuaciones (1) a (4):

$$
\mathrm{CO}_{2}(\mathrm{ac})+\mathrm{H}_{2} \mathrm{O} \Longleftrightarrow \mathrm{H}_{2} \mathrm{CO}_{3}(\mathrm{ac}) \quad \text { Ecuación (1) }
$$




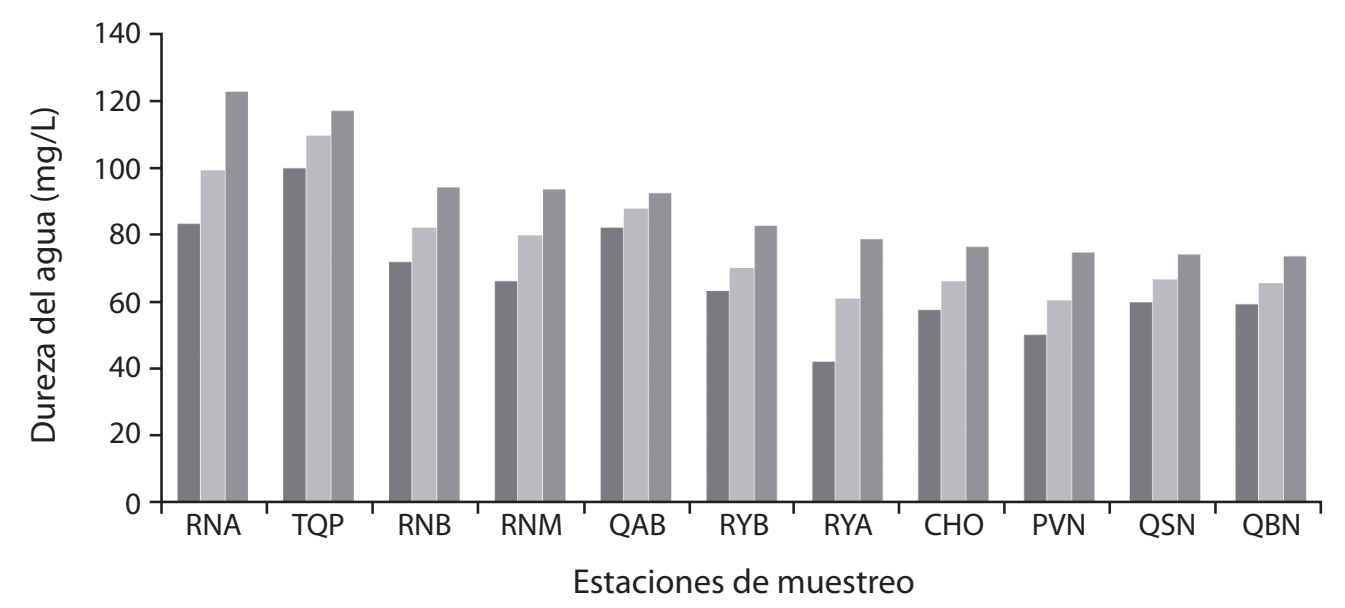

FIG. 4. Dureza total en las aguas superficiales de la cuenca del río Rincón medida entre diciembre de 2004 a setiembre de 2005.

$$
\begin{array}{ll}
\mathrm{H}_{2} \mathrm{CO}_{3}+\mathrm{H}_{2} \mathrm{O} \Longleftrightarrow \mathrm{HCO}_{3}{ }^{-}+\mathrm{H}_{3} \mathrm{O}^{+} & \text {Ecuación (2) } \\
\mathrm{HCO}_{3}{ }^{-}+\mathrm{H}_{3} \mathrm{O}^{+} \Longleftrightarrow \mathrm{H}_{2} \mathrm{CO}_{3}+\mathrm{H}_{2} \mathrm{O} & \text { Ecuación (3) } \\
\mathrm{HCO}_{3}{ }^{-}+\mathrm{OH}^{-} \Longleftrightarrow \mathrm{CO}_{3}{ }^{2-}+\mathrm{H}_{2} \mathrm{O} & \text { Ecuación (4) }
\end{array}
$$

Durante la noche la productividad primaria baja y aumenta la tasa de intercambio de $\mathrm{CO}_{2}$ atmosférico, restableciéndose el valor de $\mathrm{pH}$.

En aguas de ríos no contaminados los valores de $\mathrm{pH}$ varían entre $6,0-8,5$ y su determinación es importante, ya que tiene una gran influencia en muchos sistemas biológicos. Valores superiores o inferiores a este ámbito producen limitaciones en el desarrollo y fisiología de los organismos acuáticos, en general y en la biota de los humedales en particular.

Los cambios del pH en el agua pueden ocurrir por diversas razones, una de ellas la constituyen las prácticas agrícolas que conducen a la lixiviación de aniones hacia el subsuelo, más allá de la zona de las raíces. Típicamente los nitratos, aunque también bicarbonato, cloruros, sulfatos y aniones orgánicos, son lixiviados en asociación con cationes (calcio, magnesio y potasio), dejando un exceso de iones $\mathrm{H}^{+}$en la superficie del suelo, que luego por escurrimiento son transportados al flujo de agua. Otro fenómeno que provoca acidificación de las aguas es la lixiviación del aluminio del suelo por ácidos fuertes que lo transportan hasta el agua, y ahí en caso de que sean aguas naturalmente ricas en materia orgánica (por ejemplo ácidos húmicos), se complejará el aluminio y se liberará los iones $\mathrm{H}+$, lo que genera una reducción en el valor del $\mathrm{pH}$ del agua.
Los cambios de $\mathrm{pH}$ en ecosistemas acuáticos deben ser medidos debido a que cuando se presentan valores bajos de $\mathrm{pH}$, pueden ocurrir efectos adversos sobre peces e insectos acuáticos (CCME 1999), que afectan sus funciones fisiológicas. De acuerdo con Alabaster \& Lloyd (1982) no se presentan efectos letales sobre peces de aguas dulces en un ámbito de $\mathrm{pH}$ de 5 a 9; sin embargo, sí se han reportado efectos crónicos a valores menores a 5 , sobre todo con efectos dañinos sobre huevos y larvas (ANZECC 2000). La pérdida de poblaciones de peces ha sido atribuida a fallas en la puesta de huevos y a una disminución en la eclosión (CCME 1999). Por otro lado, también aguas con niveles de acidez bajo, tienen un impacto en las comunidades de macroinvertebrados, debido sobre todo a una disminución en las fuentes de alimentos (e.g. epiliton).

Las fluctuaciones en los valores del potencial de hidrógeno $(\mathrm{pH})$ de las aguas superficiales en la cuenca del río Rincón y sus tributarios se muestran en la Fig. 5. El ámbito de valores de $\mathrm{pH}$ medidos en la cuenca se encuentra entre 6,62 (abr-05 en CHO) y 8,17 (feb-05 en RNM), con una variación promedio y máxima de 0,5 y 1 unidades de $\mathrm{pH}$ respectivamente.

Aún cuando las estaciones de muestreo en la cuenca alta del río Rincón (RNA) y el río Pavón (PVN), están geográficamente cercanas muestran valores promedio bastante diferentes: 8,02 y 7,68 respectivamente. El río Pavón confluye en el río Rincón, por lo que después de esta estación, este último adquiere nuevas concentraciones de sustancias químicas disueltas y muestra valores promedio que corresponden al promedio entre ambas estaciones, es así que en la cuenca media del río Rincón (RNM) el valor de $\mathrm{pH}$ es 7,95. 


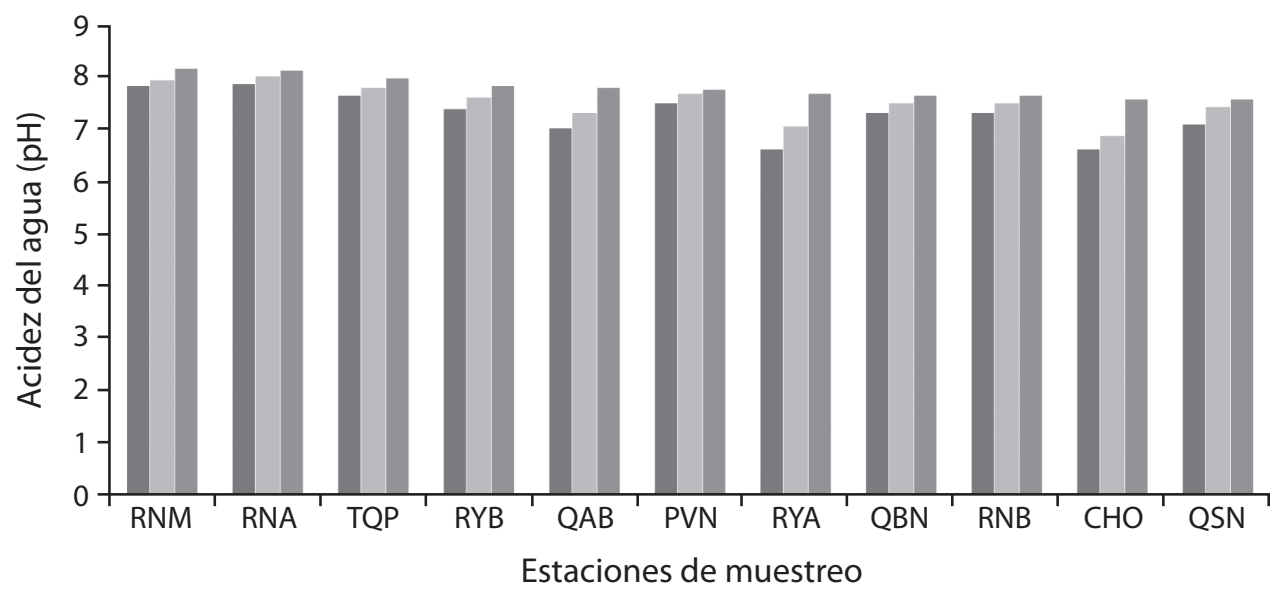

FIG. 5. Acidez $(\mathrm{pH})$ medida en las aguas superficiales de la cuenca del Río Rincón entre diciembre de 2004 y septiembre de 2005.

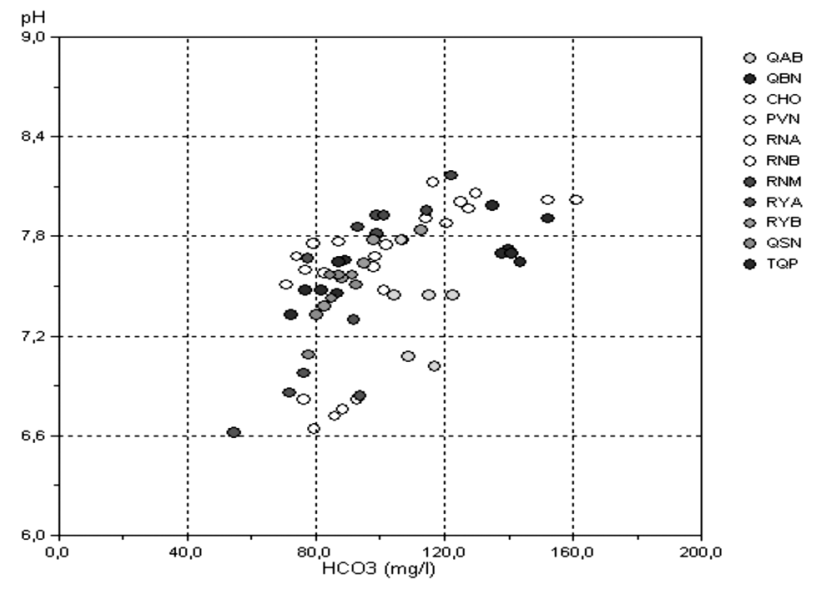

FIG. 6. Relación del pH de las aguas superficiales de la cuenca del río Rincón con la concentración de bicarbonato.

Vea ésta figura a color en la versión digital (www.uned.ac.cr/investigacio/ publicaciones/cuaderno1/).

La comparación de las mediciones de $\mathrm{pH}$ con las concentraciones de bicarbonato (Fig. 6) muestra una relación directa entre ambos parámetros, lo que puede sugerir que las aguas de la cuenca del río Rincón pueden estar controladas por un sistema de amortiguamiento del tipo bicarbonato/carbonato, sobre un sistema de ácidos húmicos y fúlvicos.

De acuerdo con las normativas de la Agencia de Protección Ambiental de los Estados Unidos y de la provincia de la Columbia Británica de Canadá, se recomienda que el ámbito de $\mathrm{pH}$ se encuentre entre 6,5 y 9; un ámbito más estrecho $(6,5$ a 8,5$)$ se indica en el Reglamento para la
Evaluación y Clasificación de Cuerpos de Agua Superficiales de Costa Rica (MINAE \& MINSA 2007).

Los valores de $\mathrm{pH}$ medidos en las aguas de la cuenca del río Rincón, durante el periodo de estudio, se encuentran dentro del ámbito recomendado en las diferentes normativas ambientales de 6,5 a 8,5 (Fig. 7).

No hubo diferencia estadísticamente significativa entre los resultados estacionales $(p>0,05 \mathrm{y} 6 \mathrm{gl})$, pero sí hubo diferencia entre los resultados temporales ( $p<0,05$ y $10 \mathrm{gl})$.

\section{Cloruro}

El cloruro se encuentra distribuido en la naturaleza, sobre todo en forma de sales solubles en agua, como cloruros de sodio y de potasio. Las mayores cantidades de cloruro en el ambiente se encuentran en los océanos. Los cloruros de potasio, calcio y magnesio pueden ser más tóxicos para organismos acuáticos que el de sodio (Benoit \& Stephan 1988)

La aplicación de sal $(\mathrm{NaCl})$ en las carreteras para evitar accidentes de invierno, en países donde nieva, representa una de las principales fuentes de contaminación antropogénica. Otras fuentes de cloruros corresponden a la disolución de depósitos de minerales que lo contienen, drenajes de agua de riego, lixiviaciones difusas, escorrentía de terrenos agrícolas, etc.

En aguas naturales, las concentraciones típicas de cloruro están en el orden de $1 \mathrm{mg} / \mathrm{L}$ a $100 \mathrm{mg} / \mathrm{L}$. El cloruro es un elemento esencial para la biota terrestre y acuática y debido a su alta solubilidad presenta pocas reacciones de precipitación y solubilización, por los que su patrón de distribución está relacionado con el movimiento del 
agua (Osorio \& Césped 2000). Su alta movilidad también le permite atravesar las membranas celulares y estar involucrado en el mantenimiento de la presión osmótica y el balance iónico del agua.

La presencia de concentraciones elevadas o fluctuantes puede tener un efecto adverso en las funciones fisiológicas normales de los organismos acuáticos, lo que causa disrupturas en la regulación de la presión osmótica, y eventualmente interfiere con el crecimiento y la reproducción. No obstante, debido a que la mayoría del cloruro es excretado del tejido animal por medio de los riñones $u$ órganos renales equivalentes, los potenciales efectos por bioacumulación son muy bajos (Nagpal et al. 2003).

La toxicidad del cloruro puede estar afectada por diferentes variables, entre ellas, la concentración de oxígeno disuelto y la temperatura. El tiempo de exposición y la presencia de otros contaminantes pueden influenciarla. Sin embargo, a la actualidad no se han encontrado referencias de estudios sistemáticos que evalúen con precisión la influencia de estas variables sobre su toxicidad.

La legislación Canadiense actual no cuenta con una norma de cloruros para la protección de organismos acuáticos de agua dulce. Sin embargo, la legislación de Columbia Británica establece un valor de concentración de $364 \mathrm{mg} \mathrm{Cl}^{-} / \mathrm{L}$ (Ministerio del Ambiente 2006), concentración a la cual una comunidad acuática puede ser expuesta indefinidamente sin causar algún efecto perjudicial. La Agencia de Protección Ambiental de Estados Unidos por su parte establece un valor de $\mathrm{CCC}$ de $230 \mathrm{mg} \mathrm{Cl}^{-} / \mathrm{L}$ y un CMC de $860 \mathrm{mg} \mathrm{Cl}^{-} / \mathrm{L}$ (USEPA 2006) y especifica claramente que estos valores corresponden cuando el cloruro está asociado al sodio y excluye plantas acuáticas, ya que estas muestran una amplia ámbito de sensibilidad al cloruro.

Las concentraciones de cloruros en la mayoría de las estaciones se encontraron por debajo del límite de cuantificación del método de análisis que se empleó en su determinación, que fue $0,63 \mathrm{mg} \mathrm{Cl}^{-} / \mathrm{L}$ (Fig. 7). Un caso particular es los ríos Rincón y Pavón, ambos presentaron las mayores concentraciones.

El río Pavón (PVN) con valores más altos que el río Rincón en la parte alta de la cuenca (RNA), mientras que en la parte media, muestra valores promedio entre ambas estaciones. Por otro lado, el agua del tanque principal (TQP) que es representativa de las nacientes, presentó concentraciones cuantificables, pero más bajos que el río Rincón y el Pavón. La laguna Chocuaco ( $\mathrm{CHO}$ ) no presentó niveles de cloruro cuantificables, en ninguna época del año; sin embargo, el río Riyito que la desagua tuvo concentraciones mayores al límite de cuantificación sobre todo en los meses más lluviosos. No obstante, estos valores estaban muy por debajo de los indicados en el Reglamento de Clasificación de Cuerpos de Agua de Costa Rica (MINAE \& MINSA2007) que es de $100 \mathrm{mg} \mathrm{Cl}^{-} / \mathrm{L}$ para la conservación del equilibrio y la protección de las comunidades acuáticas. Por otro lado, la Agencia de Protección Ambiental de Estados Unidos (USEPA 2006) establece un valor CCC de $23 \mathrm{mg} \mathrm{Cl}^{-} / \mathrm{L}$, un valor definido en términos de la concentración de cloruro máxima que se puede encontrar en el agua superficial, a las cual las comunidades acuáticas puede ser expuestas de manera continua sin causar efectos adversos.

No hubo diferencia estadísticamente significativa entre los resultados estacionales ( $p>0.05$ y 6 g.l), pero sí hubo

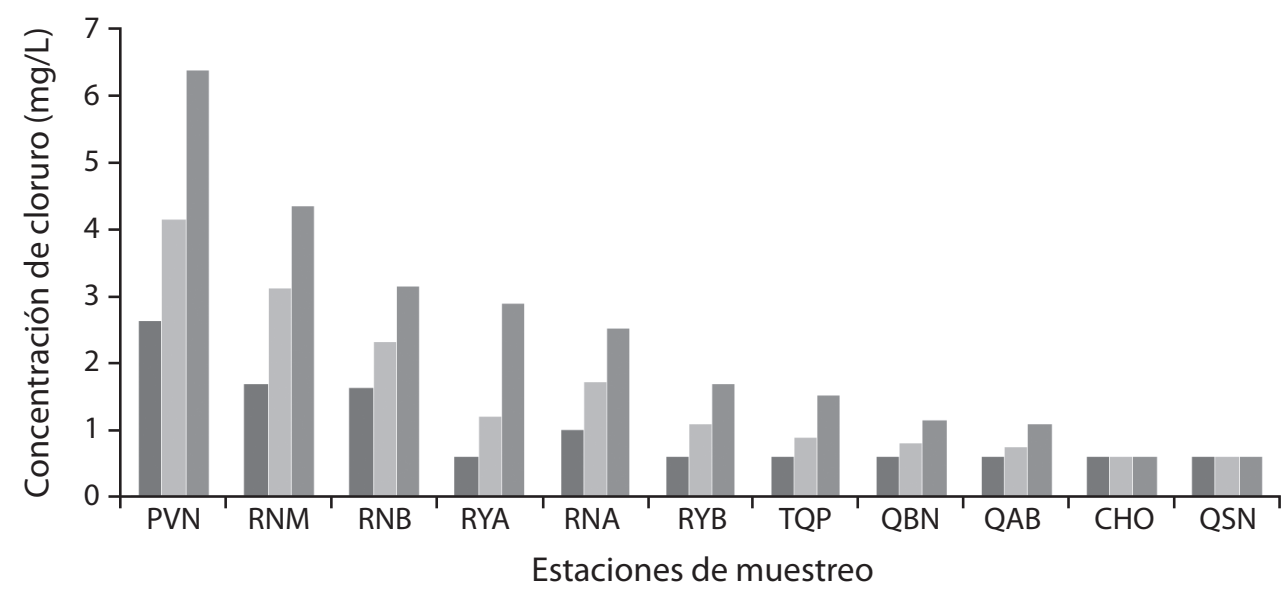

FIG. 7. Concentraciones de cloruro en las aguas superficiales de la cuenca del Río Rincón medidos entre diciembre de 2004 y setiembre de 2005. 
estadísticamente significativa entre los resultados temporales $(p<0,05$ y $10 \mathrm{gl})$.

\section{Nitratos}

Los mayores componentes del ciclo del nitrógeno son: nitrógeno $\left(\mathrm{N}_{2}\right)$, nitrógeno orgánico, amonio, nitrito y nitrato. En aguas naturales la cinética de la transformación el nitrógeno orgánico a amonio, nitritos y nitratos es dependiente de la temperatura.

Durante la respiración de las algas y su posterior muerte, una fracción del nitrógeno celular vuelve al ciclo del nitrógeno en forma de amonio. La fracción remanente se recicla en forma de nitrógeno orgánico, que experimenta descomposición bacteriana y cuyo producto final es amonio (nitrificación). La desnitrificación por parte de los sedimentos en el fondo de la columna de agua puede ser uno de los principales mecanismos de pérdida en algunos sistemas. Tanto el amonio como el nitrato están disponibles para ser usado por las plantas, aunque por razones fisiológicas la forma preferida de nitrificación es el amonio (Lopes 2005).

El nitrógeno es un elemento esencial para las plantas. Los compuestos de nitrógeno son necesarios y una parte integral de los ecosistemas acuáticos debido a que es un nutrimento esencial en la producción fotosintética y bacteriana. Sin embargo, un suministro excesivo puede producir importantes desequilibrios nutricionales en las plantas que se traducen en crecimientos excesivos, retraso de la época de maduración, pérdida de calidad de las cosechas, etc. El exceso de nitrógeno, además de ser perjudicial para las plantas, aumenta la lixiviación de nitrato y la contaminación de las aguas subterráneas.

El nitrógeno se transporta a través de sus formas orgánicas e inorgánicas como consecuencia de las condiciones ambientales y de acciones microbianas. En ambientes acuáticos las formas predominantes son: nitratos, nitritos y amonio.

Los efectos en organismos acuáticos de estos compuestos nitrogenados pueden ser no sólo por su toxicidad sino también por la reducción del oxígeno disuelto (Nordin \& Pommen 1986).

Las principales fuentes naturales localizadas de nitratos son las rocas ígneas y la actividad volcánica. Los niveles de concentración en aguas naturales varían dependiendo de la productividad biológica; en lagos y arroyos oligotróficos, se espera que el nitrato sea menor que $0.1 \mathrm{mg} / \mathrm{L}$ $\mathrm{NO}_{3}{ }^{-}\left(\mathrm{NO}_{3}-\mathrm{N}\right)$. En lagos eutróficos concentraciones superiores a los $0.2 \mathrm{mg} / \mathrm{L} \mathrm{NO}_{3}{ }^{-}-\mathrm{N}$ tienden a estimular el crecimiento de algas. Por otro lado cuerpos de agua con ni- veles sobre $5 \mathrm{mg} / \mathrm{L} \mathrm{NO}_{3}{ }^{-}-\mathrm{N}$ muestran una clara señal de contaminación (Nordin \& Pommen 1986).

El nitrato es altamente móvil debido a que no se liga al suelo o a partículas en el agua. Aunque es a menudo liberado en forma de sal (nitrato de sodio, nitrato de potasio o nitrato de amonio), rápidamente se disuelve y libera el ion nitrato. Durante los periodos de lluvia, el nitrato que no es absorbido por las plantas en la superficie del suelo, viaja hacia las aguas subterráneas o superficiales. Cuando alcanza aguas con un bajo nivel de oxígeno disuelto, cierto tipo de bacterias lo convierten a nitrito y finalmente a nitrógeno gaseoso $\left(\mathrm{N}_{2}\right)$, que se escapa a la atmósfera.

El nitrato es un nutrimento esencial para las plantas, aunque en concentraciones altas puede generar un crecimiento excesivo de plantas y algas. Cuando el fitoplancton se descompone consume oxígeno y reduce su disponibilidad. Algunos invertebrados acuáticos y peces expuestos a concentraciones de nitratos, sobre todo en sus primeras etapas de vida, experimentan problemas de crecimiento, maduración lenta o menor éxito reproductivo, y bajo condiciones extremas la muerte.

No es posible recomendar un único valor de nitrato que proteja contra la eutrofización de un cuerpo de agua, debido a que depende de la abundancia de otros nutrimentos (por ejemplo amonio, fósforo y sílice), del movimiento del agua y de la cantidad de luz disponible. Por tanto, las guías sólo son recomendaciones dirigidas a proteger los organismos acuáticos de los efectos tóxicos directos del nitrato. Según la Normativa Canadiense (CCME 1999) el valor sugerido para la protección de la vida acuática de los efectos directos del nitrato, es de $13 \mathrm{mg} \mathrm{NO}_{3}{ }^{-} / \mathrm{L}$. Este valor es superior al propuesto en la regulación costarricense de $5 \mathrm{mg} \mathrm{NO}_{3}{ }^{-} / \mathrm{L}$ para la conservación del equilibrio natural de las comunidades acuáticas y $<10 \mathrm{mg} \mathrm{NO}_{3}{ }^{-} / \mathrm{L}$ para la protección de las comunidades acuáticas.

Los resultados del análisis de nitratos en las agua de la cuenca del río Rincón determinados en el período de estudio, comprendido entre diciembre del año 2004 y septiembre del 2005, no fueron cuantificables; excepto en QAB y RNA que estuvieron cercanos a los $2 \mathrm{mg} \mathrm{NO}_{3}^{-} / \mathrm{L}$ (Fig. 8).

\section{Fósforo total}

En aguas relativamente tranquilas, como lagos y lagunas, la presencia de nutrimentos (fósforo y nitrógeno) es un factor crítico, por su potencial para desequilibrar el ecosistema y originar fenómenos de eutrofización antropogénica (Pérez 2004). Las plantas acuáticas, algas y lirios, van a proliferar debido a la presencia de un exceso de estos elementos nutritivos, que actúan como fertilizantes y cuya principal fuente es la escorrentía agrícola. Esta 


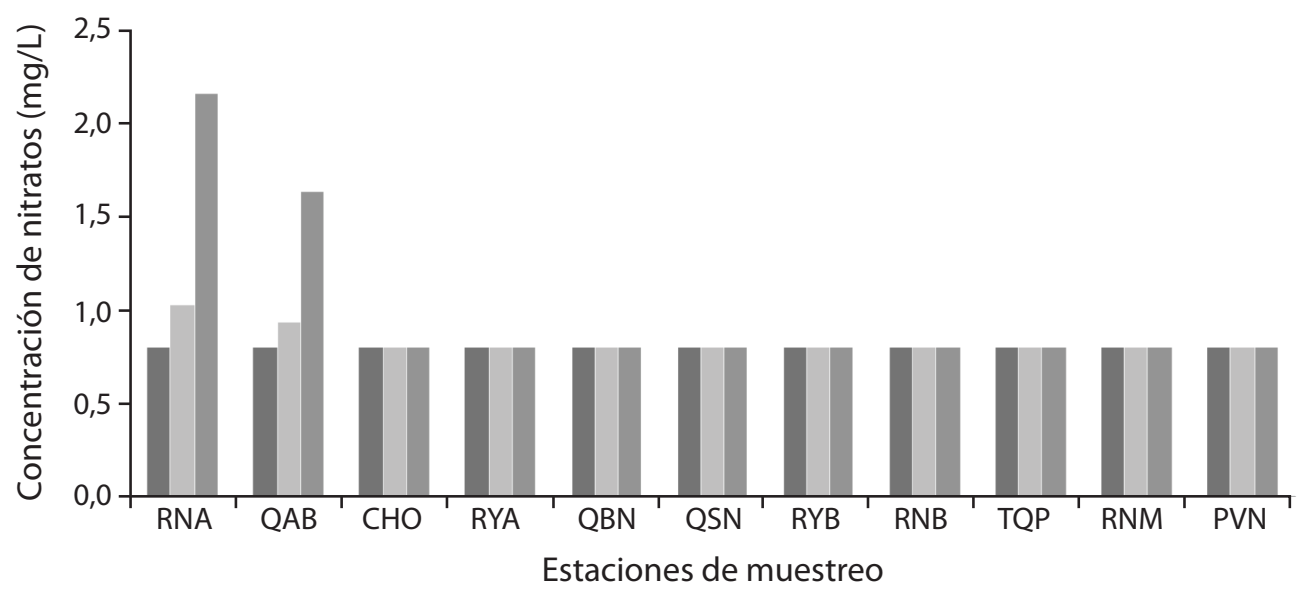

FIG. 8. Concentración de nitratos en las aguas superficiales de la cuenca del Río Rincón medidos entre diciembre de 2004 y setiembre de 2005.

proliferación genera una cantidad grande de masa vegetal en la capa superficial del agua y su posterior acumulación sobre las riberas. Cuando las plantas mueren, se hunden y en su descomposición consumen el oxígeno disuelto en el agua, lo que provoca condiciones anaeróbicas.

El fósforo es un macronutriente esencial; es acumulado por amplia variedad de seres vivos. Tiene un papel importante en la construcción de los ácidos nucleicos y en el almacenamiento y uso energético en las células. En aguas no impactadas, es fácilmente utilizado por las plantas y convertido a las estructuras celulares por acción fotosintética (Holmes 1996).

Es considerado como el principal nutrimento a considerarse en el control del grado de eutroficación de un ecosistema acuático, ya que influye directamente en el crecimiento de las algas y por tanto puede afectar la actividad productiva primaria del agua (lqbal et al. 2006).

Naturalmente se encuentra como fosfatos (ortofosfatos, fosfatos condensados y fosfatos enlazados orgánicamente) (lqbal et al. 2006). En aguas frescas no contaminadas se encuentra en bajas concentraciones. Los ortofosfatos y los fosfatos condensados provienen de la aplicación de fertilizantes en suelos para cultivos agrícolas. Los fosfatos orgánicos son formados por procesos biológicos. Por otro lado, las formas inorgánicas del fósforo son principalmente fosfatos enlazados a hierro y calcio (Aminot \& Andrieux 1996).

La descomposición de algas acuáticas y el consumo nocturno de oxígeno durante los procesos de respiración, generan descensos en los niveles de oxígeno y potencialmente producen la muerte de peces. En algunos sistemas de aguas dulces, el afloramiento de cianobacterias en particular es un síntoma prominente de eutrofización. En ocasiones el afloramiento de cierto tipo de cianobacterias en aguas usadas para abrevadero puede ocasionar la muerte de ganado (lqbal et al. 2006).

Es difícil encontrar guías para la regulación de los niveles recomendados de fósforo en aguas naturales, puesto que no es un elemento tóxico y es también un nutrimento requerido y limitante es las aguas naturales, ya que en bajas concentraciones estimula la productividad acuática.

Para un cuerpo de agua en particular, se debe considerar una lista de factores que afectan la naturaleza del fósforo como contaminante: uno de ellos es las amplias variaciones en los niveles de fósforo total en las aguas naturales, debido a la región y a diferencias específicas en las condiciones locales, tales como: la geología, el tipo de suelo, la química del agua, la densidad de población. También, sobresale el hecho de que el detrimento en la calidad del agua como un efecto indirecto del fósforo, se debe como se ha mencionado al crecimiento de algas y a las depleciones en las concentraciones del oxígeno disuelto.

Los efectos en la productividad primaria son modificados por factores naturales que atenúan la luz, por ejemplo el carbono orgánico disuelto o la turbiedad y modifican por tanto la alta productividad cuando hay concentraciones altas de fósforo.

Algunos sistemas tienen niveles bajos de fósforo total y pueden ser descritos como oligotróficos. Otros sistemas tienen naturalmente altas concentraciones de fósforo total y se describen como eutróficos. Debido a estos motivos no es posible establecer un único valor guía para 
fósforo total. En su lugar, se proponen en general sistemas de referencia para el manejo de un sitio especifico, basados principalmente en enfoques ecoregionales.

Las ecoregiones denotan áreas de similitud general en ecosistemas y en el tipo, calidad y cantidad de recursos ambientales y son diseñadas para servir como una estructura espacial para la investigación, el establecimiento, el manejo y el monitoreo de ecosistemas y componentes de ecosistemas. Tienen aplicación en las necesidades inmediatas de las agencias ambientales (por ejemplo USEPA, Environment Canada) para seleccionar sitios de referencia e identificar aguas de alta calidad, desarrollar criterios fisicoquímicos y biológicos para una eco-región y el manejo integral de ecosistemas (Bailey 1980).

El enfoque ecoregional usa ámbitos de concentraciones de fósforo deseadas para un sistema específico de aguas naturales. El ámbito apropiado se determina de acuerdo con la información de la línea base y los objetivos o metas de manejo para el sistema. Si los niveles de fósforo en el sistema exceden en $50 \%$ el nivel de la línea base o del límite superior del ámbito, puede haber problemas ambientales (CCME 2005). Los ámbitos de concentraciones de fósforo en lagos y ríos canadienses son los que se muestran en el Cuadro 2. La legislación ambiental de Manitoba (Williamson 2002) es clara al definir que se deben evitar concentraciones en las cuales se promueva el crecimiento de plantas flotantes, hongos o bacterias.

Las fluctuaciones en las concentraciones de fósforo total en las aguas superficiales en la cuenca del río Rincón se muestran en la Fig. 9. Todos los sitios de muestreo estuvieron caracterizados por presentar bajas concentraciones de fósforo $(<0,0013 \mathrm{mg} \mathrm{P} / \mathrm{L})$.

CUADRO 2

Clasificación trófica para lagos y ríos Canadienses (CCME 2005)

\begin{tabular}{lc}
\hline Estado Trófico & Fósforo Total (mg P/L) \\
\hline Ultra-Oligotrófico & $<0,004$ \\
Oligotrófico & $0,004-0,010$ \\
Mesotrófico & $0,010-0,020$ \\
Meso-Eutrófico & $0,020-0,035$ \\
Eutrófico & $0,035-0,100$ \\
Hiper eutrófico & $>0,100$
\end{tabular}

Aunque la estación QBN mostró una concentración máxima $(0,0115 \mathrm{mg} \mathrm{P} / \mathrm{L})$ en el mes de septiembre; no obstante, no alcanzó los 0,050mg P/L. Esta situación pudo deberse, a que durante los periodos de lluvia al aumentar el flujo de agua, la disponibilidad y la distribución espacial de los niveles de fósforo pueden aumentar también, por la escorrentía de los suelos y la re-suspensión del material depositado en el lecho del río. No obstante, las concentraciones máximas de fósforo medidas fueron datos aislados; por lo que, no tiene mucha relevancia como si lo hubiese tenido el hecho de que se presentaran concentraciones altas por periodos prolongados de tiempo. Es importante destacar que las medidas aisladas proporcionan una base muy pobre para el establecimiento de la condición trófica de un ecosistema acuático. Es realmente el seguimiento sistemático el que da la base para las estimaciones de las consecuencias biológicas del fósforo.

Por otro lado, aguas con un bajo impacto o ausentes de ellas, usualmente presentan una relación de N:P mayor que (25-40):1, mientras que las más impactadas tienen relaciones $\mathrm{N}: P$ de menos de 10:1; en todos los casos al realizar estos cálculos las relaciones fueron superiores a 40:1.

Aunque, el límite de cuantificación del método de análisis de fósforo total del Laboratorio de Calidad de Aguas no fue suficientemente bajo para establecer una clasificación trófica de las aguas, sí se pudo determinar que la condición durante el período del estudio dista de una situación eutrófica (Fig. 9). Y lo más importante, las ligeras variaciones presentadas no fueron estadísticamente significativas tanto entre los resultados estacionales ( $p>0,05$ y $6 \mathrm{gl}$ ) como temporales ( $p>0,05$ y $10 \mathrm{gl}$ ).

\section{Calcio}

El calcio es un metal alcalino térreo y uno de los cationes más abundantes en aguas subterráneas y superficiales. Es fácilmente disuelto de las rocas ricas en minerales que lo contienen como calcita y dolomita, por el agua de escorrentía o de lluvia. Las sales de calcio, junto con las de magnesio, provocan la dureza del agua.

La presencia de calcio en aguas naturales varía de acuerdo con la proximidad a la fuente natural. Típicamente se encuentra en concentraciones menores a $15 \mathrm{mg}$ $\mathrm{Ca}^{2+} / \mathrm{L}$, mientras que en aguas cercanas a rocas carbonatadas pueden estar en el ámbito de $30 \mathrm{mg} \mathrm{Ca}^{2+} / \mathrm{L}$ a $100 \mathrm{mg}$ $\mathrm{Ca}^{2+} / \mathrm{L}$. Las aguas residuales contribuyen de manera importante a las concentraciones de calcio en las aguas superficiales. La lluvia ácida puede incrementar el lixiviado de los iones calcio del suelo.

El calcio es esencial para la nutrición humana. También ayuda a mantener la estructura de las células de las 


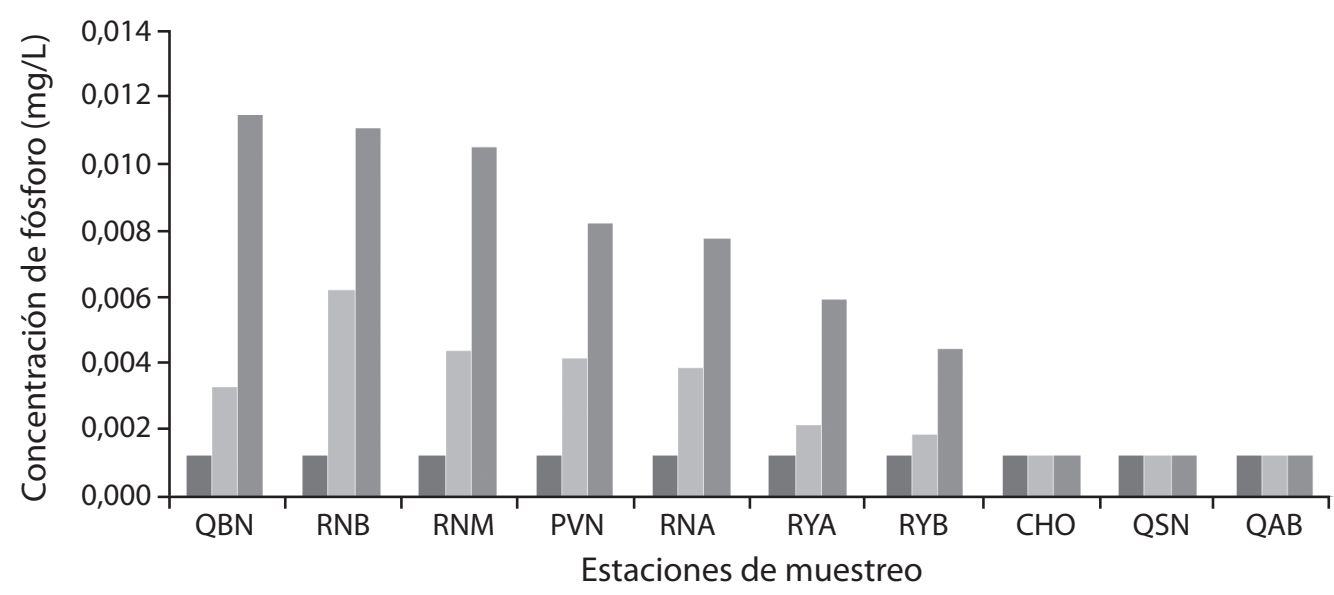

FIG. 9. Concentraciones de fósforo total en las aguas superficiales de la cuenca del Río Rincón medidos entre diciembre de 2004 y setiembre de 2005.

plantas y es deseable en aguas de riego debido a que mejora la estructura del suelo. Las altas concentraciones de calcio en el agua no son dañinas para la mayoría de los organismos acuáticos y puede más bien reducir la toxicidad en peces de algunos compuestos químicos.

Los resultados de las mediciones de calcio se muestran en la Fig. 10. El ámbito de concentraciones fue de $8,93 \mathrm{mg}$ $\mathrm{Ca}^{2+} / \mathrm{L}$ a $34,5 \mathrm{mg} \mathrm{Ca}{ }^{2+} / \mathrm{L}$. La parte alta de la cuenca presentó los valores más altos (RNA), mientras que en la laguna Chocuaco (CHO) y los afluentes del río Riyito (QSN, QBN) se midieron las menores concentraciones de calcio (Fig. 10).

Los valores obtenidos en las aguas de la cuenca del río Rincón, durante el periodo de estudio, se encontraron dentro del ámbito de concentraciones recomendado de acuerdo con las diferentes normativas ambientales.

No hubo diferencia estadísticamente significativa entre los resultados obtenidos en una misma temporada de muestreo $(p=0,81$ y $g l=5)$; sin embargo, las variaciones entre estaciones de muestreo sí fueron estadísticamente significativas $(p=0,0001$ y $g \mathrm{l}=10)$.

\section{Magnesio}

El magnesio está presente en las aguas como ion $\mathrm{Mg}^{2+}$ y junto con el calcio, provoca la dureza del agua. Proviene principalmente de los minerales ferromagnésicos y de algunas rocas que contienen carbonatos. Se encuentra también en la clorofila, en diferentes compuestos organometálicos, en materia orgánica y es un elemento esencial para los seres vivos. Su concentración natural varía entre $1 \mathrm{mg} / \mathrm{L}$ y hasta $100 \mathrm{mg} / \mathrm{L}$, dependiendo del tipo de roca de que provenga. Aunque, el magnesio es empleado en procesos industriales, el aporte de las aguas residuales en magnesio a las concentraciones totales en aguas superficiales, es relativamente bajo.

De acuerdo con el Reglamento para la Evaluación y Clasificación de Cuerpos de Agua Superficiales de Costa Rica (MINAE \& MINSA 2007) se establece un valor de $8,7 \mathrm{mg}$ $\mathrm{Mg}^{2+} / \mathrm{L}$ como valor recomendado para la conservación y desarrollo de la vida acuática.

Los resultados de los análisis de magnesio se muestran en la figura11. El ámbito de concentraciones fue de $3,92 \mathrm{mg} \mathrm{Mg}^{2+} / \mathrm{L}$ a $10,87 \mathrm{mg} \mathrm{Mg}^{2+} / \mathrm{L}$, la concentración promedio fue de $7,3 \mathrm{mg} \mathrm{Mg}^{2+} / \mathrm{L}$ con una desviación estándar de 1,6mg Mg${ }^{2+} / \mathrm{L}$. La estación de muestreo QAB mostró la mayor concentración promedio $9,87 \mathrm{mg} \mathrm{Mg}^{2+} / \mathrm{L}$. En general las concentraciones obtenidas se encontraron dentro de los ámbitos de concentraciones naturales, y no representan ningún impacto en la conservación y preservación de la vida acuática.

Las variaciones obtenidas para una misma temporada de muestreo ( $p=0,022$ y gl $=5)$ como las variaciones entre estaciones de muestro sí son estadísticamente significativas $(p=0,0001$ y $g l=10)$.

\section{Conductividad}

La conductividad es una medida de la capacidad del agua de conducir una corriente eléctrica. Es sensible a las variaciones de sólidos disueltos, principalmente de sales minerales. Para un cuerpo de agua en específico, se relaciona con los sólidos totales disueltos y con los iones 


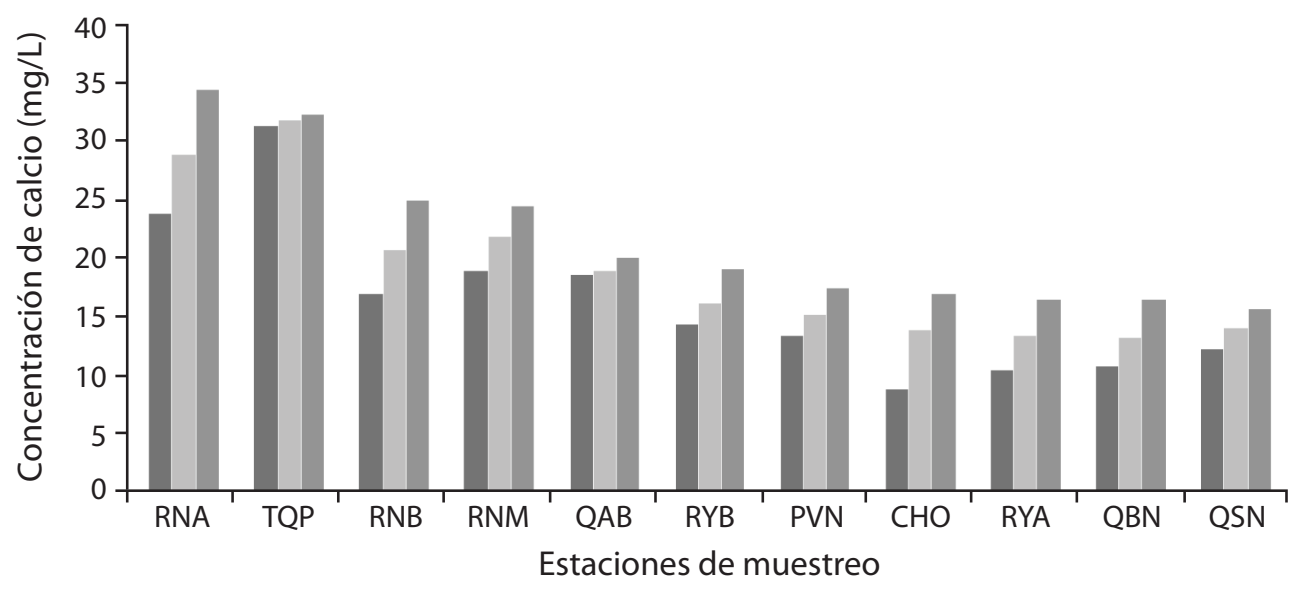

FIG. 10. Concentración de calcio en las aguas superficiales de la cuenca del Río Rincón medidos entre diciembre de 2004 y setiembre de 2005.

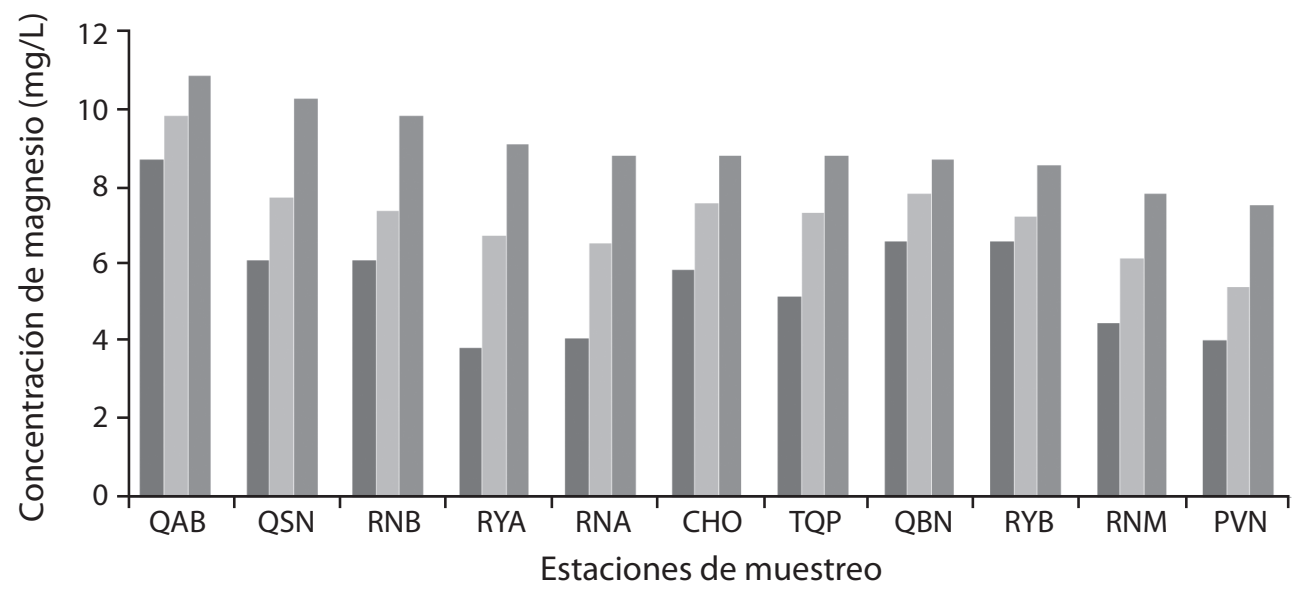

FIG. 11. Concentración de magnesio en las aguas superficiales de la cuenca del Río Rincón medidos entre diciembre de 2004 y setiembre de 2005.

mayoritarios (Chapman 1996). La conductividad de la mayoría de las aguas dulces naturales se encuentra entre los $10 \mu \mathrm{S} / \mathrm{cm}$ a los $350 \mu \mathrm{S} / \mathrm{cm}$; aunque, por supuesto depende del tipo de geología. En zonas con influencia marino costera los valores pueden ir desde los $125 \mu \mathrm{S} /$ $\mathrm{cm}$ hasta los $2200 \mu \mathrm{S} / \mathrm{cm}$; mientras que en lagos y reservorios las conductividades son por lo general más bajas (ANZECC 2000).

El análisis de las medidas de conductividad eléctrica obtenidas en diferentes puntos de la cuenca del río Rincón, durante el periodo de estudio, presentaron el comportamiento indicado en la figura 12. La conductividad promedio medida en las aguas superficiales de la cuenca en estudio fue de $161,8 \mu \mathrm{S} / \mathrm{cm}$, con un ámbito desde $92,7 \mu \mathrm{S} / \mathrm{cm}$ hasta $249,6 \mu \mathrm{S} / \mathrm{cm}$. La conductividad promedio más baja $(122,3 \mu \mathrm{S} / \mathrm{cm})$ correspondió a las mediciones realizadas en RYA, ligeramente por debajo del CHO, QBN y QSN. Mientras que el promedio de mediciones más altas fueron las de TQP; con un promedio de $219,4 \mu \mathrm{S} / \mathrm{cm}$. Por su parte el río Rincón en la parte alta de la cuenca (RNA) presentó valores muy cercanos a TQP. Cuando las aguas del río Rincón se mezclan con las del Pavón (PVN), el primero obtiene características de ambos; así la conductividad en la estación RNM fue de 179,9uS/ $\mathrm{cm}$, un valor medio entre los medidos en la parte alta y los medidos en PVN $(141,3 \mu \mathrm{S} / \mathrm{cm})$. 
No hubo diferencia estadísticamente significativa entre los resultados obtenidos en una misma temporada de muestreo $(p=0,81 ; a=0,05 ; g l=5)$; sin embargo, las variaciones entre estaciones de muestro sí fueron estadísticamente significativas $(p=0,0001 ; \alpha=0,05 ; g l=10)$.

La relación hallada entre la conductividad y el calcio y el magnesio, presentes en las aguas superficiales se ilustra en las figuras 13 y 14.

\section{Sulfatos}

El azufre es un elemento no metálico que se encuentra en numerosos minerales, incluyendo pirita ( $\mathrm{FeS})$, barita $\left(\mathrm{BaSO}_{4}\right)$, epsomita $\left(\mathrm{MgSO}_{4} \bullet 7 \mathrm{H}_{2} \mathrm{O}\right)$, yeso $\left(\mathrm{CaSO}_{4} \bullet 2 \mathrm{H}_{2} \mathrm{O}\right)$ y rocas sedimentarias. Cuando el azufre hexavalente se combina con oxígeno, forma el ion sulfato $\left(\mathrm{SO}_{4}{ }^{2-}\right)$ que es estable y fácilmente soluble en agua, a excepción de

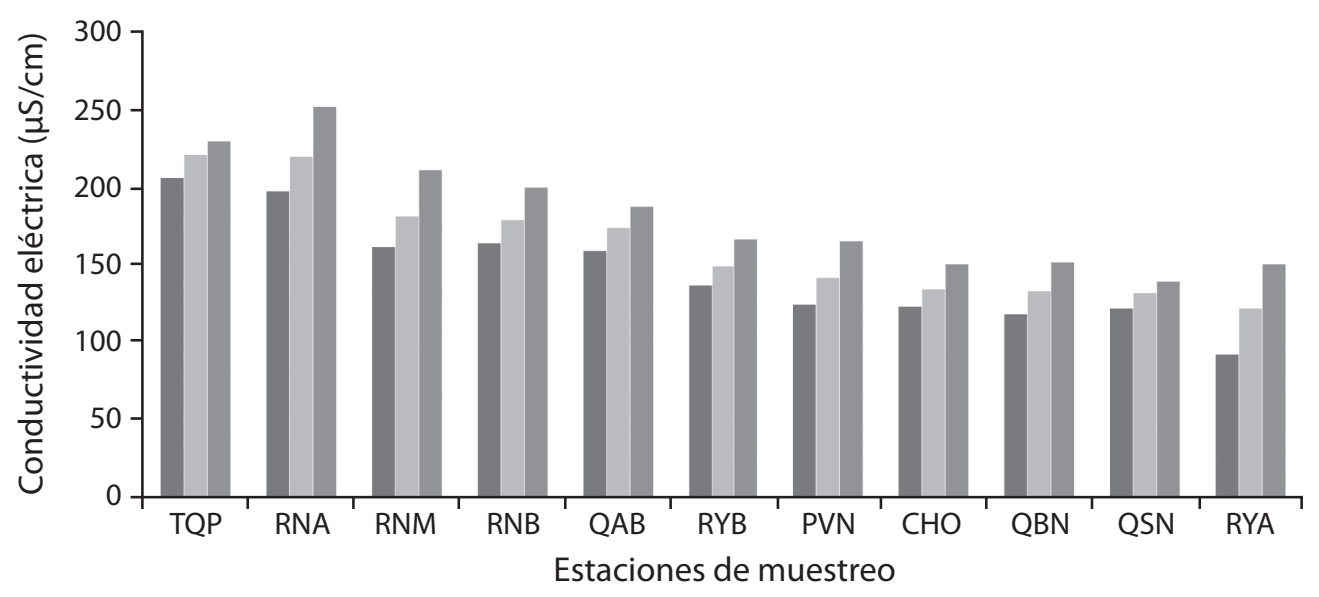

FIG. 12. Conductividad eléctrica en las aguas superficiales de la cuenca del Río Rincón medidos entre diciembre de 2004 y setiembre de 2005.

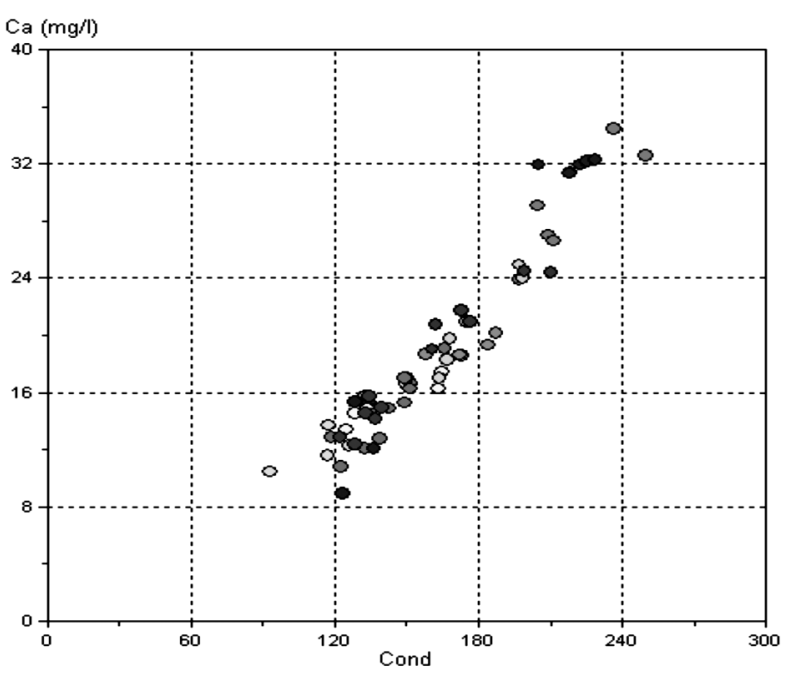

FIG. 13. Relación entre la conductividad y el calcio en las aguas superficiales de la cuenca del río Rincón.

Vea ésta figura a color en la versión digital (www.uned.ac.cr/investigacio/ publicaciones/cuaderno1/).

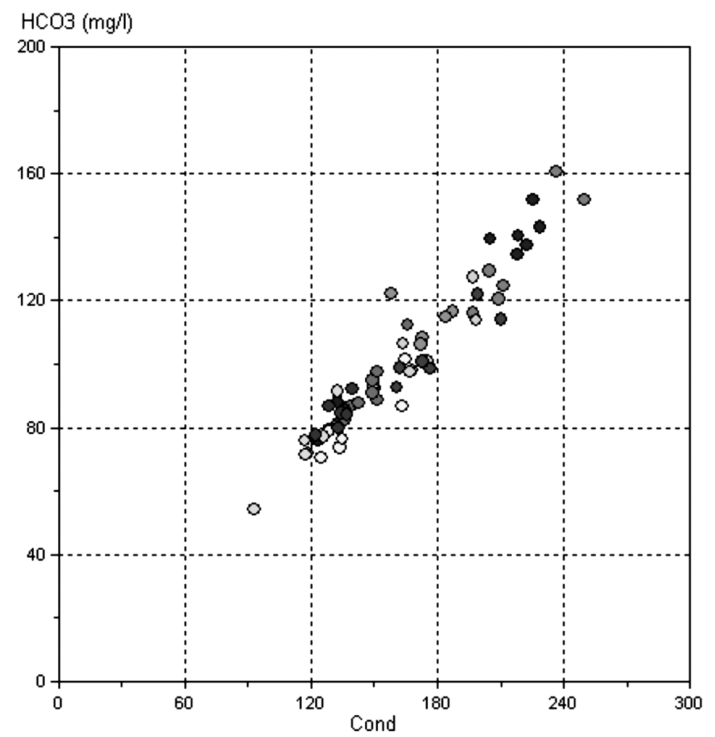

FIG. 14. Relación entre la conductividad y el bicarbonato en las aguas superficiales de la cuenca del río Rincón.

Vea ésta figura a color en la versión digital (www.uned.ac.cr/investigacio/ publicaciones/cuaderno1/) 
los sulfatos de plomo, bario y estroncio que precipitan. Las fuentes naturales del azufre incluyen: volcanes, descomposición y combustión de materia orgánica y sales marinas. Los sulfatos pueden ser usados como fuente de oxígeno por algunas bacterias que convierten el sulfato a $\mathrm{HS}^{-} \mathrm{o} \mathrm{H}_{2} \mathrm{~S}$ bajo condiciones anaeróbicas.

Los sulfatos son descargados al ambiente acuático a través de las aguas residuales. La quema de combustibles fósiles es también una fuente importante de sulfuro a la atmósfera. La mayoría de las emisiones provocadas por el hombre a la atmósfera, cerca del $95 \%$, son en forma de $\mathrm{SO}_{2}$.

Las descargas de aguas residuales de industrias que usan sulfatos y ácido sulfúrico y por deposición atmosféricas. En aguas naturales no contaminadas, comúnmente las concentraciones de sulfato disuelto varía de $2 \mathrm{mg}$ $\mathrm{SO}_{4}{ }^{2} / \mathrm{L}$ a $80 \mathrm{mg} \mathrm{SO}_{4}{ }^{2-} / \mathrm{L}$, aunque las fluctuaciones estacionales son muy normales en la mayoría de los ríos.

No se han reportado en la literatura importantes casos de toxicidad por sulfato en organismos acuáticos, incluyendo peces y musgos acuáticos. De acuerdo con la Normativa Canadiense, la concentración máxima permisible de sulfatos para vida acuática en aguas de río es de $100 \mathrm{mg} \mathrm{SO}_{4}{ }^{2-} / \mathrm{L}$, siendo el valor de concentración de alerta de 50mg/L (Ministerio del Ambiente 2006).

Los resultados de los análisis de sulfatos se muestran en la figura 15. La mayoría de las estaciones no presentaron valores de concentración cuantificables (L.C. $=0,67 \mathrm{mg}$ $\mathrm{SO}_{4}{ }^{2-} / \mathrm{L}$ ), el ámbito estuvo entre $0,67 \mathrm{mg} \mathrm{SO}_{4}{ }^{2-} / \mathrm{L}$ y $9,59 \mathrm{mg}$ $\mathrm{SO}_{4}{ }^{2-} / \mathrm{L}$. La estación de muestro localizada en la parte alta del río Rincón (RNA) mostró la mayor concentración promedio $7,6 \mathrm{ppm} \mathrm{SO}_{4}{ }^{2-}$; sin embargo, estos resultados no alcanzaron los niveles considerados como máximos permisibles, ni siquiera la concentración de alerta según la Normativa Canadiense (CCME 1999), para la conservación de la vida acuática en aguas de río, que es de $100 \mathrm{mg}$ $\mathrm{SO}_{4}{ }^{2} / \mathrm{L}$ y $50 \mathrm{mg} \mathrm{SO}_{4}{ }^{2-} / \mathrm{L}$ respectivamente.

Las variaciones presentadas no fueron estadísticamente significativas para los resultados de las estacionales ( $p>0,05$ y $6 \mathrm{gl})$; sin embargo, sí fueron las variaciones temporales $(p>0,05$ y $10 \mathrm{gl})$.

\section{Sodio y Potasio}

Las concentraciones de ion sodio en aguas naturales superficiales varían de manera considerable dependiendo de las condiciones geológicas locales, descargas de aguas residuales y en algunos países del uso estacional de sal en carreteras. Los valores pueden oscilar entre $1 \mathrm{mg} \mathrm{Na}^{+} / \mathrm{L}$ o menos a $10 \mathrm{mg} \mathrm{Na}+/ \mathrm{L}$. La Organización Mundial de la Salud (OMS 2006) establece un límite de $200 \mathrm{mg} / \mathrm{L}$ en el agua de consumo humano. Algunas aguas superficiales, incluyendo aquellas que reciben descargas de aguas residuales tienen valores de concentración debajo de los $50 \mathrm{mg} / \mathrm{L}$. Aunque las aguas subterráneas pueden exceden los $50 \mathrm{mg} \mathrm{Na}+\mathrm{L}$.

La sodificación de suelos (natural o antropogénica) provoca efectos negativos sobre la producción y la productividad de cultivos porque deteriora sus propiedades físicas. Este deterioro se manifiesta en una drástica disminución en la conductividad hidráulica o en la tasa de infiltración del agua en el suelo y puede ser difícil de corregir porque requiere la utilización conjunta de enmiendas,

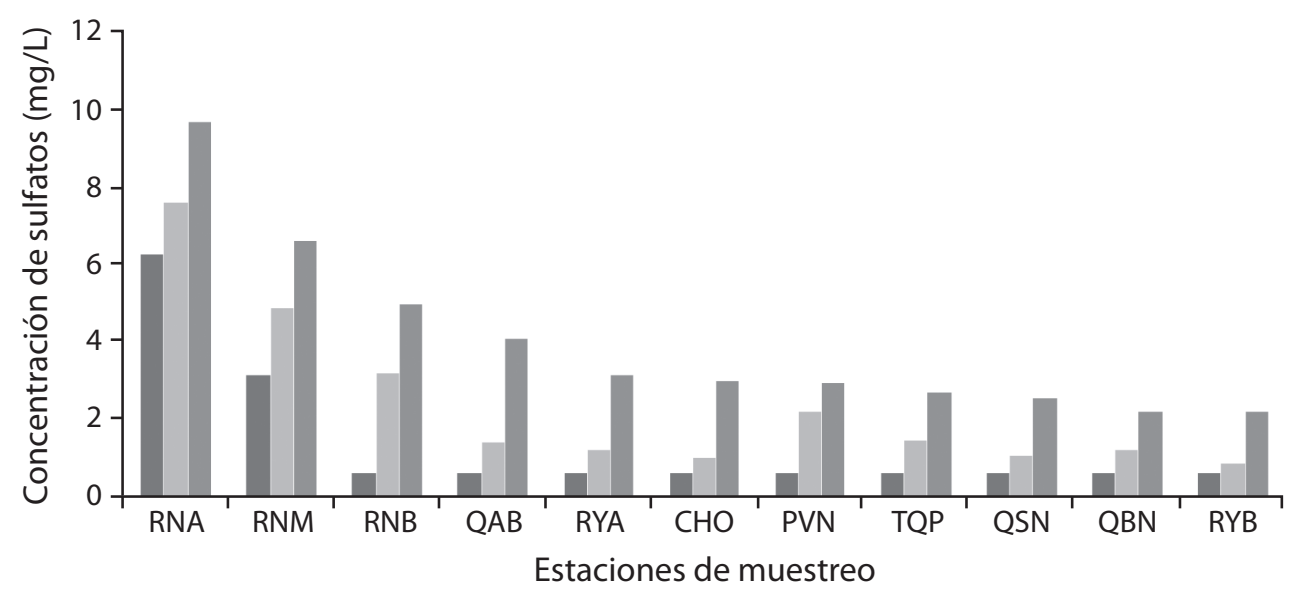

FIG. 15. Concentración de sulfatos en las aguas superficiales de la cuenca del Río Rincón medidos entre diciembre de 2004 y setiembre de 2005. 
grandes volúmenes de agua y complicados sistemas de drenaje (Guerrero 2004).

La acumulación del sodio en el suelo tiene dos efectos principales; en primer lugar si es absorbido como ión, al acumularse es tóxico para las plantas y si es absorbido por las arcillas, sustituye al calcio y al magnesio, lo que provoca cambios en la estructura que afectan la permeabilidad del suelo y el crecimiento de las plantas.

El peligro de sodificación depende de la concentración relativa y absoluta de los cationes en el agua, de los cuales los principales son el calcio, el magnesio y el sodio. Si la proporción de sodio es alta, es mayor el problema, pero si predomina el calcio y magnesio, es menor.

Por otro lado, en aguas naturales las concentraciones de potasio son menores a $10 \mathrm{mg} \mathrm{K}^{+} / \mathrm{L}$, aunque puede aumentar por depositación atmosférica, escorrentía de terrenos agrícolas e influencia de drenajes de irrigación.

Dado que son elementos esenciales, para la nutrición de las plantas, su presencia en el agua es beneficiosa.

Los resultados de los análisis de sodio y potasio se muestran en las Fig. 16 y 17. Mientras que por una lado, de acuerdo con el valor del límite de cuantificación del LCA $\left(0,89 \mathrm{mg} \mathrm{K}^{+} / \mathrm{L}\right)$, no se determinó la presencia del ión potasio; en la mayoría de las estaciones se determinaron concentraciones de sodio mayores al límite de cuantificación $(0,3 \mathrm{mg} \mathrm{Na}+/ \mathrm{L})$.

El ámbito de concentraciones fue de $0,3 \mathrm{mg} \mathrm{Na} / \mathrm{L}$ a 9,54mg Na+/L. La estación de muestro localizada en la parte alta del río Rincón (RNA) mostró la mayor concentración promedio 8,3ppm $\mathrm{Na}^{+}$, para este parámetro en las aguas del río Pavón (PVN) se determinó una concentración promedio de 6,8ppm $\mathrm{Na}^{+}$, una vez que se habían mezclado ambos cuerpos de agua, RNM mostró valores promedio (7,3ppm $\left.\mathrm{Na}^{+}\right)$entre ambas estaciones.

No obstante, debido a que el sodio afecta principalmente la estructura del suelo y por tanto es un factor importante en el agua de riego e incluso en aguas de consumo humano puede afectar las funciones renales, cardiacas y circulatorias. No hay referencia regulatoria o el impacto que sus concentraciones puedan tener en la conservación y preservación de la vida acuática.

Las variaciones presentadas en los resultados de sodio no fueron estadísticamente significativas para los resultados de las variaciones estacionales ( $p>0,05$ y $6 \mathrm{gl}$ ); sin embargo, sí los fueron las variaciones temporales ( $\mathrm{p}>0,05$ y $10 \mathrm{gl})$.

\section{Bicarbonato}

La alcalinidad es una medida de la capacidad de neutralización del agua. Indica la presencia de carbonatos, bicarbonatos e hidróxidos y menos significativamente de boratos, silicatos, fosfatos y sustancias orgánicas. Se expresa como equivalentes de carbonato de calcio $\left(\mathrm{CaCO}_{3}\right)$. La composición de las especies de la alcalinidad depende del pH, la composición mineral, la temperatura y la fuerza iónica; sin embargo, normalmente se interpreta como una función de los carbonatos, bicarbonatos e hidróxidos (McNeely et al. 1979).

Su presencia en las aguas naturales es importante ya que contribuye a mantener el balance iónico y a evitar

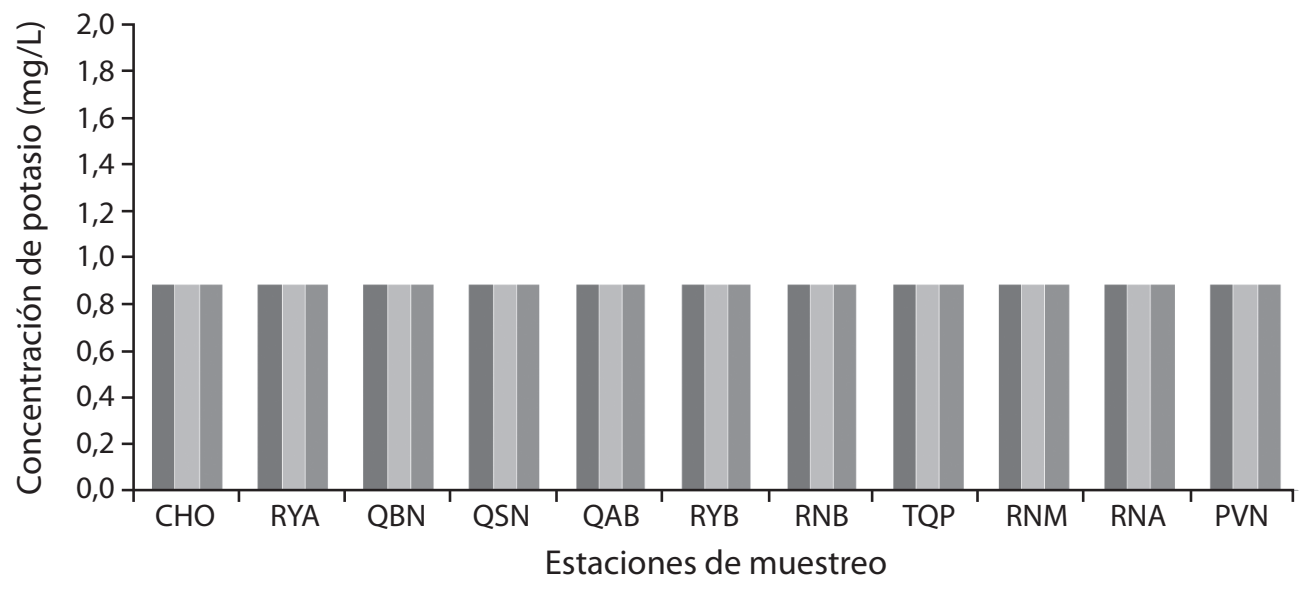

FIG. 16. Concentración de potasio en las aguas superficiales de la cuenca del Río Rincón medidos entre diciembre de 2004 y setiembre de 2005. 
propiedades corrosivas o incrustantes, raramente excede los $500 \mathrm{mgCaCO}_{3} / \mathrm{L}$.

Para proteger la vida acuática, las guías estipulan que la alcalinidad se debe mantener a los niveles naturales propios del área, sin variaciones drásticas.

Los resultados de los análisis de bicarbonato se muestran en la figura 18. El ámbito de concentraciones fue de 54,3mg $\mathrm{HCO}_{3}{ }^{-} / \mathrm{L}$ a $160,8 \mathrm{mg} \mathrm{HCO}_{3}{ }^{-} / \mathrm{L}$. La estación de muestro localizada en la parte alta del río Rincón (RNA) mostró la mayor concentración promedio $134,1 \mathrm{mgHCO}_{3}^{-} / \mathrm{L}$, para este parámetro es las aguas del río Pavón (PVN) se determinó una concentración promedio de 81,4ppm $\mathrm{HCO}_{3}^{-}$, una vez que se habían mezclado ambos cuerpos de agua, RNM mostró valores promedio $\left(104,7 \mathrm{mg} \mathrm{HCO}_{3}{ }^{-} / \mathrm{L}\right)$ entre ambas estaciones. Las concentraciones de bicarbonato están íntimamente ligadas con la geología de la zona de estudio, que está caracterizada por las rocas aflorantes que son de tipo basáltica sedimentaria.

Las variaciones presentadas no fueron estadísticamente significativas para los resultados estacionales $(p>0,05$ y $6 \mathrm{gl})$; sin embargo, sí fueron las variaciones temporales ( $p>0,05$ y $10 \mathrm{gl})$.

\section{Temperatura}

La temperatura es un parámetro físico descriptivo de un sistema que caracteriza el calor, o transferencia de energía térmica, entre ese sistema y otros. Desde un

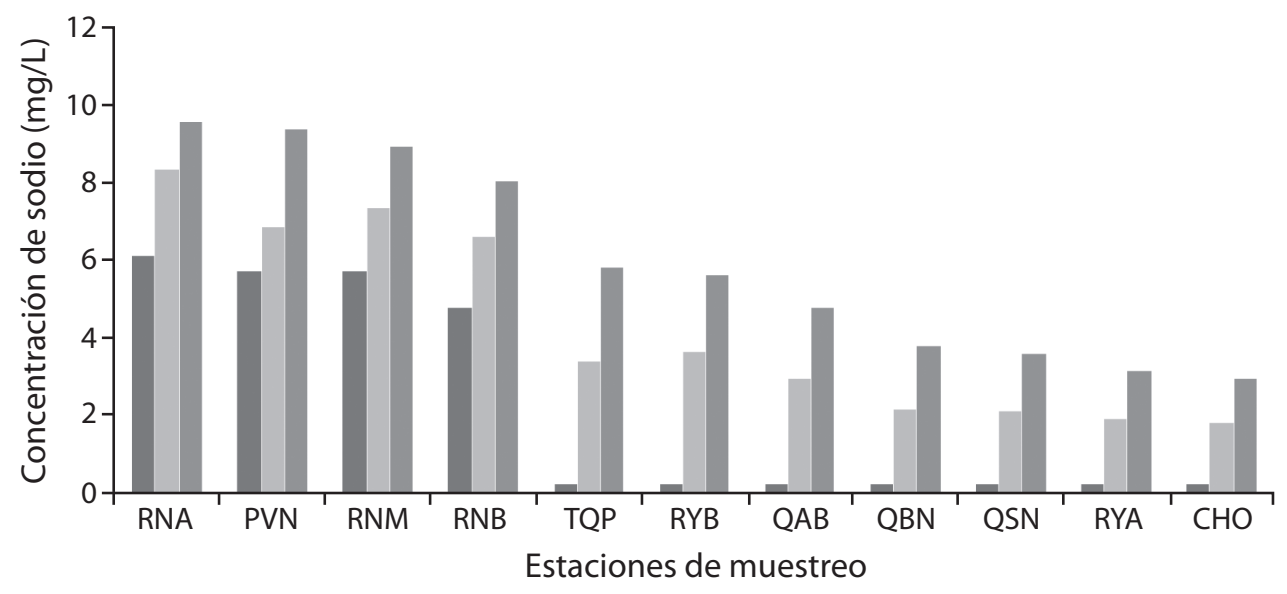

FIG. 17. Concentración de sodio en las aguas superficiales de la cuenca del Río Rincón medidos entre diciembre de 2004 y setiembre de 2005.

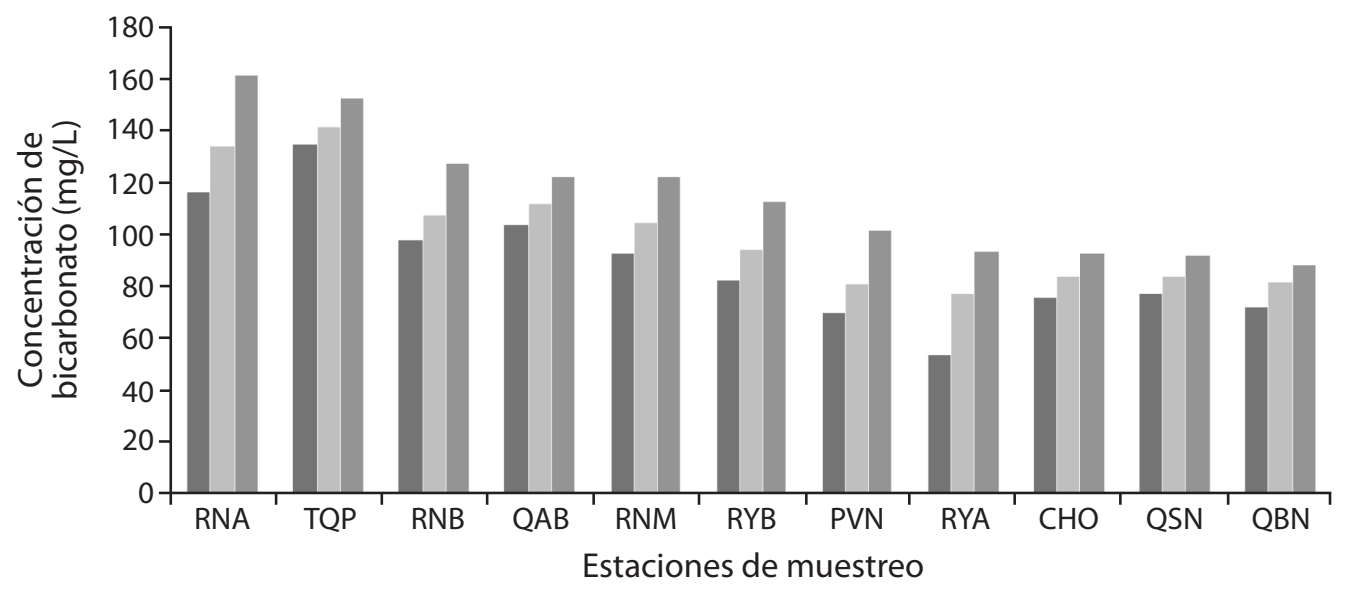

FIG. 18. Concentración de bicarbonato en las aguas superficiales de la cuenca del Río Rincón medidos entre diciembre de 2004 y setiembre de 2005. 
punto de vista microscópico, es una medida de la energía cinética asociada al movimiento aleatorio de las partículas que componen el sistema. Afecta tanto los procesos físicos (volatilización, solubilidad de sales y gases, estratificación de estanques), como los procesos químicos $(\mathrm{pH}$, equilibrio de ionización, velocidad de reacción) (Osorio \& Césped 2000).

La temperatura del agua también influencia los procesos fisiológicos de los organismos, tales como la respiración microbiana, que es responsable, en gran parte, de la autopurificación que ocurre en los cuerpos de agua (Chapman 1996). Altas temperaturas favorecen una mayor tasa de crecimiento, lo cual permite que cierto tipo de biota alcance poblaciones significativas. Bajo condiciones naturales la temperatura del agua que fluye varía entre $0^{\circ} \mathrm{C}$ y $30^{\circ} \mathrm{C}$, sin embargo, los valores recomendados para la conservación de la vida acuática dependerán del caso en particular de que se trate, debido a que la temperatura depende entre otros factores: de la hora del día y época del año, condiciones del tiempo, flujo y profundidad de la corriente.

Los resultados de las mediciones de temperatura se muestran en la figura 19. El ámbito fue de $22,0^{\circ} \mathrm{C}$ a $32,5^{\circ} \mathrm{C}$, con un valor promedio de $26,8^{\circ} \mathrm{C}$. Mientras que la desviación estándar promedio fue $1,3^{\circ} \mathrm{C}$, RNB presentó la mayor variación $\left(2,5^{\circ} \mathrm{C}\right)$ durante la temporada de estudio.

Hubo diferencias estadísticamente significativas entre los resultados obtenidos en una misma temporada de muestreo ( $p=0,81$ y $\mathrm{gl}=5$ ) como entre estaciones de muestro $(p=0,0001 ; y g l=10)$.

\section{Oxígeno disuelto}

El oxígeno disuelto es uno de los parámetros más importantes para la vida acuática y la ecología de los ríos. Puede ser removido o agregado al agua por varios procesos fisicoquímicos o reacciones biológicas. Cuando las concentraciones de oxígeno caen abajo del nivel de saturación, el déficit se compensa por la transferencia de gas desde la atmósfera a través de la superficie y cuando las concentraciones son superiores al nivel de saturación, la sobresaturación se reduce por la transferencia desde la columna de agua al aire. Tales interacciones son controladas por el diferencia de las presiones parciales en la fase gaseosa y de las concentraciones en la fase líquida. La transferencia de oxígeno en aguas naturales depende de la mezcla interna y la turbulencia debido a los gradientes de velocidad y a las fluctuaciones, temperatura, viento, cataratas, pantanos, rápidos y películas superficiales (Lopes 2005).

El oxígeno es esencial en organismos aeróbicos para el sistema de transporte de electrones hacia la mitocondria. La insuficiencia de oxígeno en la mitocondria genera reducción en la energía celular y la subsecuente pérdida del balance iónico en los fluidos circulatorios y celulares. Si la insuficiencia persiste, ocurre la muerte, aunque algunos animales poseen rutas metabólicas anaeróbicas, las cuales pueden retrasar la letalidad por periodos cortos de tiempo (minutos a días). La anaerobiosis está bien desarrollada en algunos organismos bentónicos, tales como bivalvos, moluscos y poliquetos; pero no en otros grupos, como peces y crustáceos (Hammen 1976). No hay evidencia de que

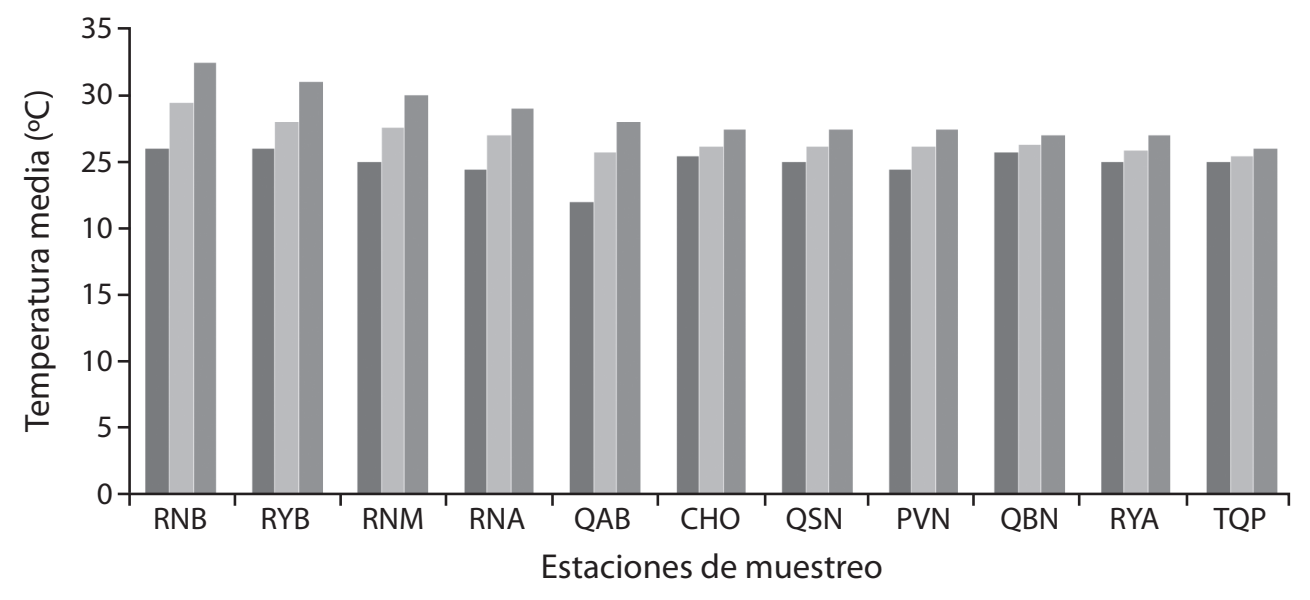

FIG. 19. Temperatura medida en las aguas superficiales de la cuenca del Río Rincón entre diciembre de 2004 y setiembre de 2005. 
cualquier ser vivo que habite aguas costeras o estuarinas puedan vivir en condiciones anaeróbicas.

Un cuerpo de agua que tenga un nivel de oxígeno disuelto abajo de $3 \mathrm{mg} \mathrm{O}_{2} / \mathrm{L}$ es considerado hipóxico. El bajo contenido de oxígeno o depleción del oxígeno por lo general resulta de la combinación de una alta productividad biológica y un intercambio de agua reducido (Dai et al. 2006).

Algunos animales acuáticos se han adaptado a cortos periodos de hipoxia y anaerobiosis, tomando más oxígeno y transportándolo más efectivamente a las células y a la mitocondria, lo cual significa que ventilan sus superficies respiratorias más intensamente e incrementan su ritmo cardiaco. Si a pesar de estas repuestas no se logra mantener el pH sanguíneo, la capacidad de transporte de oxígeno decrece. Un comportamiento temprano puede ser moverse rápido hacia aguas más oxigenadas. Sin embargo, si la hipoxia persiste, los animales pueden reducir el nado y la alimentación, lo cual reducirá su necesidad de energía y por tanto de oxígeno.

La reducción motora puede hacer al organismo acuático más tolerante a corto tiempo, pero no soluciona el problema a largo plazo. La disminución en la locomoción aumenta la vulnerabilidad a depredadores y la reducción de la alimentación afecta el crecimiento (Thursby et al. 2000).

Los resultados de las mediciones de la concentración de oxígeno disuelto (OD) se muestran en la figura 20. Los niveles de $\mathrm{OD}$ en la laguna Chocuaco ( $\mathrm{CHO}$ ) se encuentran cercanos a cero, debido a la ausencia de movimiento del agua; como consecuencia el río Riyito presenta niveles bastantes bajos aunque superiores $\mathrm{CHO}$, gracias a la incorporación de oxígeno por el flujo turbulento del agua.
Para el resto de las estaciones el valor promedio de OD fue de $7,7 \mathrm{mg} \mathrm{O}_{2} / \mathrm{L}$ suficiente para mantener y conservar la vida acuática de las especies más sensibles. No obstante, QAB presentó en dos ocasiones valores abajo del ámbito recomendado de $6,5 \mathrm{mg} \mathrm{O}_{2} / \mathrm{L}$ a $8,5 \mathrm{mg} \mathrm{O}_{2} / \mathrm{L}$.

En consecuencia las diferencias fueron estadísticamente significativas tanto entre los resultados obtenidos en una misma temporada de muestreo $(p=0,81 \mathrm{y} \mathrm{gl}=5)$ como entre estaciones de muestro $(p=0,0001 ; y g l=10)$.

\section{Mapas de calidad de agua}

En las siguientes figuras se muestran los Mapas de Calidad del Agua de la cuenca del río Rincón, los cuales fueron construidos con toda la información fisicoquímica recabada en el período de este estudio; Nótese que la cuenca fue dividida en 11 sub áreas, las cuales fueron dibujadas considerando las sub-cuencas representativas para cada punto de muestreo (ver Cuadro 1). Se seleccionaron parámetros representativos, y se empleo la concentración o el valor promedio obtenido en cada uno de las sub-cuencas como indicador para la construcción de los mapas. En primera instancia se creó el mapa de Dureza Total (Fig. 21) de las aguas superficiales.

En términos generales las aguas superficiales de la cuenca del río Rincón estuvieron caracterizadas por valores bajos de carbonato de calcio ( $<120 \mathrm{mg} \mathrm{CaCO}_{3} / \mathrm{L}$ ) pero predominantes de calcio (Ver Clasificación Hidrogeoquímica).

El mapa de alcalinidad (Fig. 22) es uno de los más interesantes, ya que representa las concentraciones de bicarbonatos disueltos en las aguas superficiales de la cuenca del río Rincón y que por tanto puede considerarse como

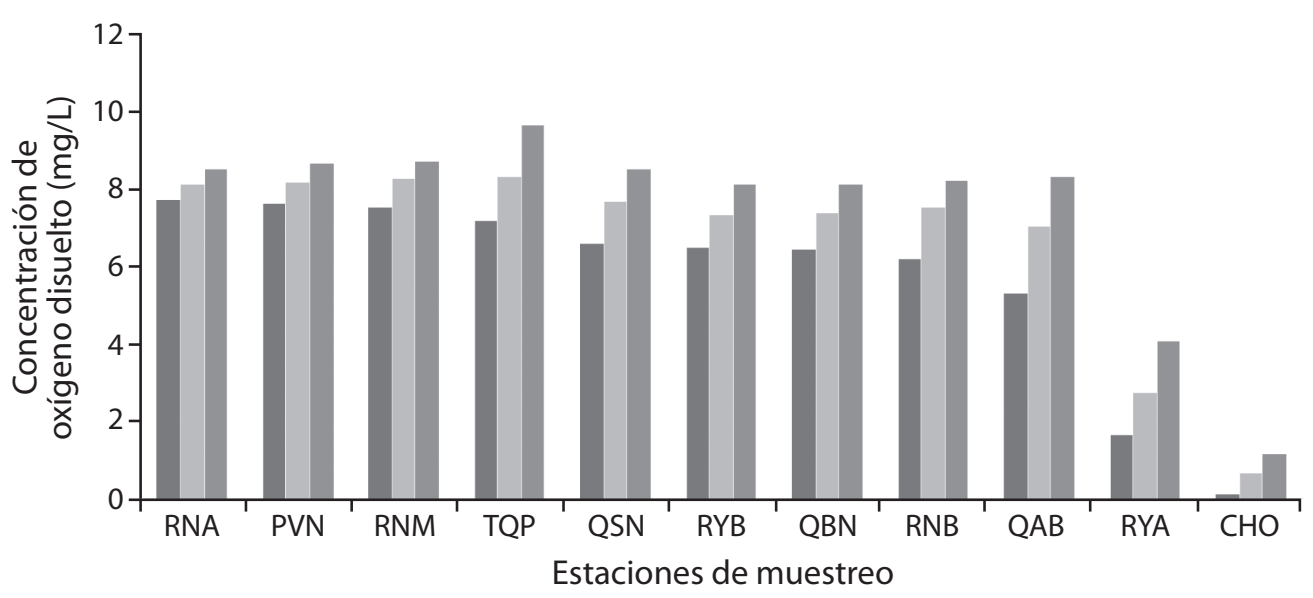

FIG. 20. Concentraciones de oxígeno disuelto medidas en las aguas superficiales de la cuenca del Río Rincón entre diciembre de 2004 y setiembre de 2005. 


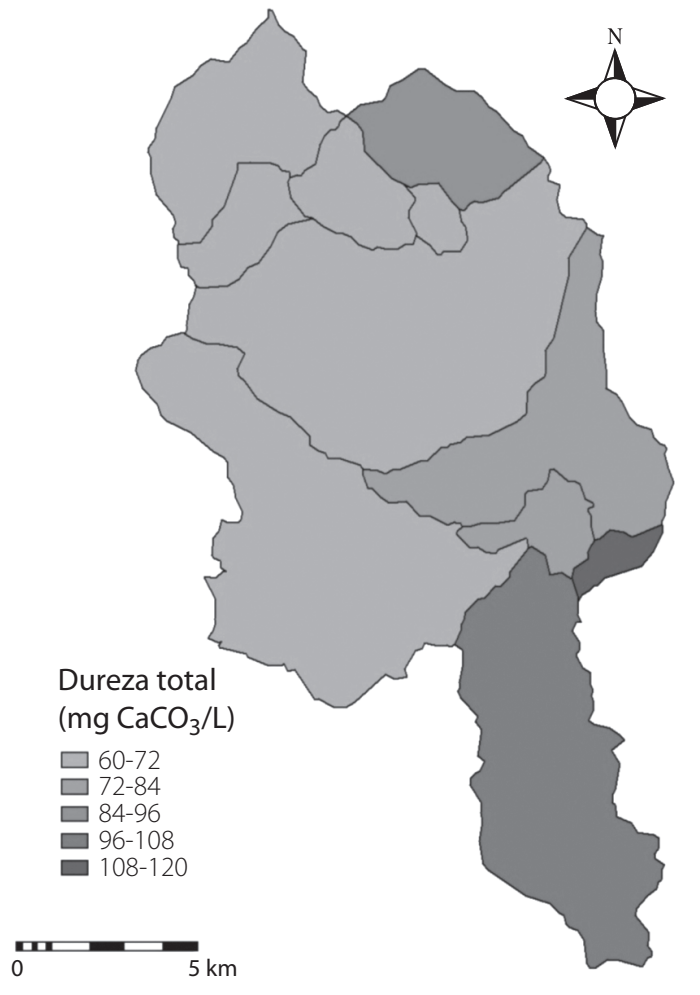

FIG. 21. Dureza total en las aguas superficiales de la cuenca del río Rincón en la Península de Osa.

Vea a color ésta figura y las posteriores en la versión digital (wWW uned.ac.cr/investigacio/publicaciones/cuaderno1/).

una estimación de las condiciones geológicas de los depósitos de minerales. Los procesos bioquímicos y geoquímicos que ocurren sobre estos depósitos, afectan la disolución de los minerales, y en conjunto con las precipitaciones atmosféricas constituyen la litología dominante en las aguas superficiales. Por otro lado, factores como el clima, el escurrimiento, y la influencia antropogénica, que también controlan la hidroquímica de las aguas naturales, causan variaciones en las concentraciones de los minerales disueltos. En este sentido, la determinación de esta línea base reviste especial importancia por cuanto a futuro las variaciones en las concentraciones podrían emplearse como un indicador del impacto causado sobre la cuenca.

La estación TQP mostró los valores más altos de conductividad con un promedio de $219,4 \mu \mathrm{S} / \mathrm{cm}$ (Fig. 23). Las variaciones de color entres las estaciones de muestro sí fueron estadísticamente significativas ( $p=0,0001 ; a=0,05 ; g l=10$ ).

El mapa de fósforo total (Fig. 24) muestra las fluctuaciones en las concentraciones de este nutrimento en las aguas superficiales en la cuenca del río Rincón. En general las sub-cuencas estuvieron caracterizadas por valores

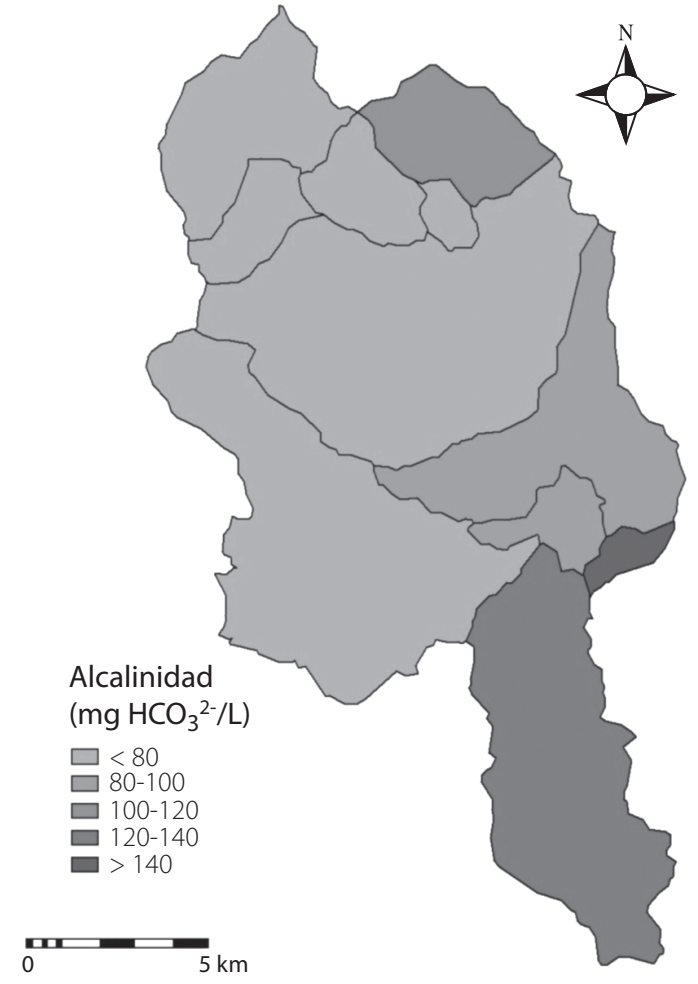

FIG. 22. Alcalinidad en las aguas superficiales de la cuenca del río Rincón en la Península de Osa.

bajos de fósforo $(<0,0013 \mathrm{mg} \mathrm{P} / \mathrm{L})$. Las concentraciones máximas de fósforo medidas fueron datos aislados; por lo que, no tienen relevancia como si lo hubiese tenido el hecho de que se presentaran concentraciones altas por periodos prolongados de tiempo. Las medidas aisladas no proporcionan una base para el establecimiento de la condición trófica de un ecosistema acuático.

A continuación se muestra el mapa del oxígeno disuelto (Fig. 25), si bien es cierto las concentraciones de este parámetro pueden variar por muchos factores, fue posible determinar que en algunas estaciones de muestreo, que en este mapa representan sub-cuencas, como la laguna Chocuaco las concentraciones medidas están por debajo de $1 \mathrm{mg} \mathrm{O}_{2} / \mathrm{L}$ sin importar la época del año; por otro lado, la parte alta del río Riyito presentó medidas entre de $1 \mathrm{mg}$ $\mathrm{O}_{2} / \mathrm{L}$ y de $3 \mathrm{mg} \mathrm{O}_{2} / \mathrm{L}$. El río Riyito desagua la laguna Chocuaco, conforme avanza hacia su desembocadura en el Golfo Dulce, los niveles de oxigenación alcanzan niveles normales $\left(6,5 \mathrm{mg} \mathrm{O}_{2} / \mathrm{L}\right.$ a de $\left.8,5 \mathrm{mgO}_{2} / \mathrm{L}\right)$.

El resto de la cuenca muestra valores apropiados para el desarrollo y la conservación de la vida acuática. 


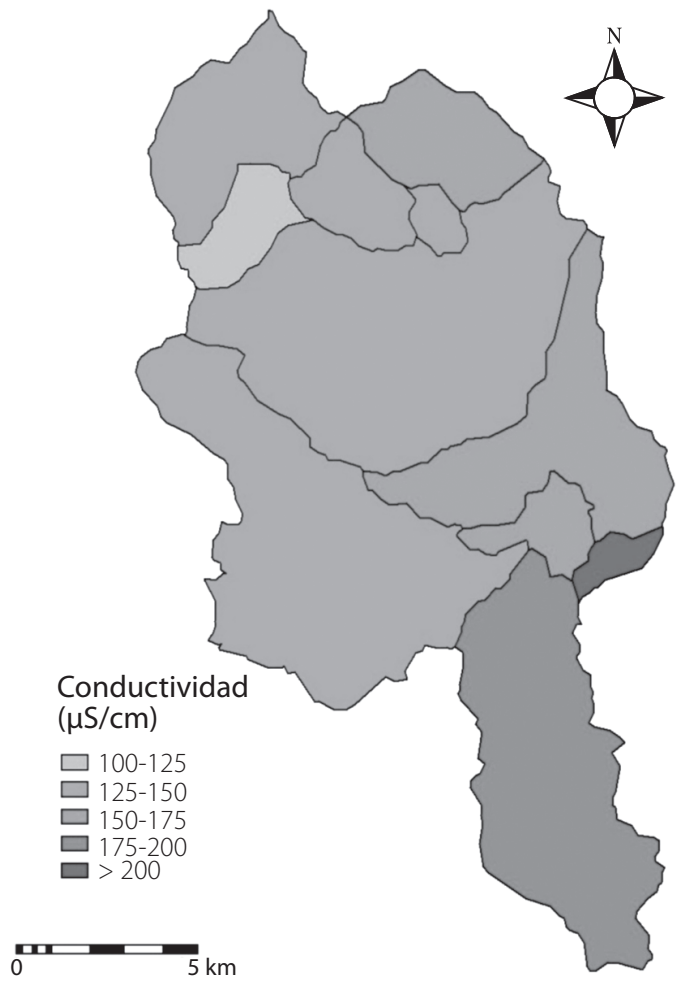

FIG. 22. Alcalinidad en las aguas superficiales de la cuenca del río Rincón en la Península de Osa.

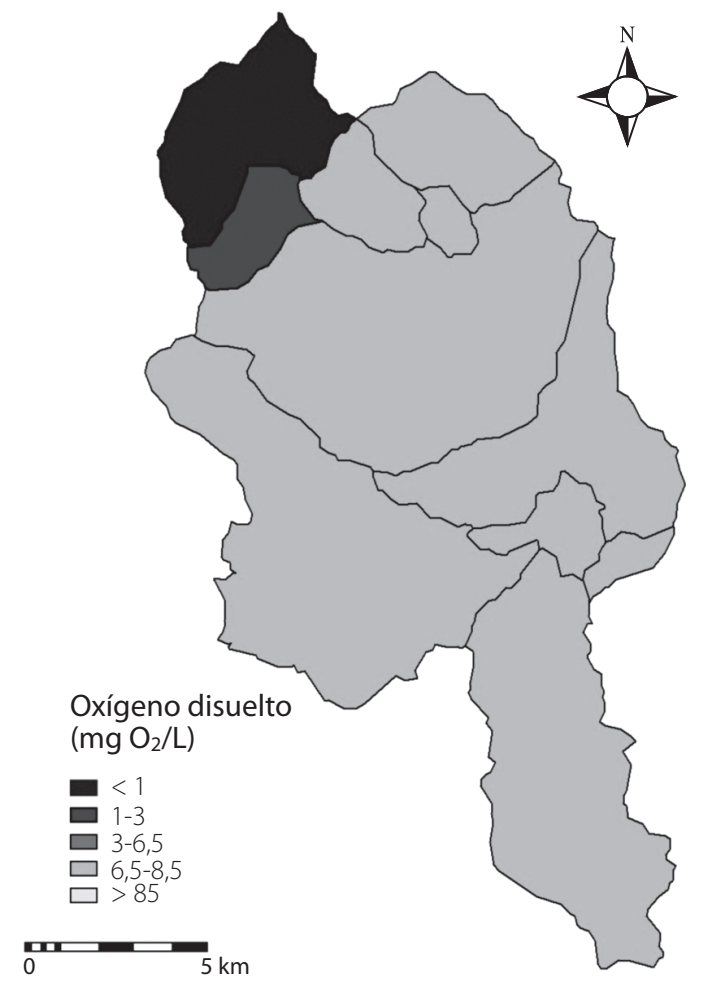

FIG. 22. Alcalinidad en las aguas superficiales de la cuenca del río Rincón en la Península de Osa.

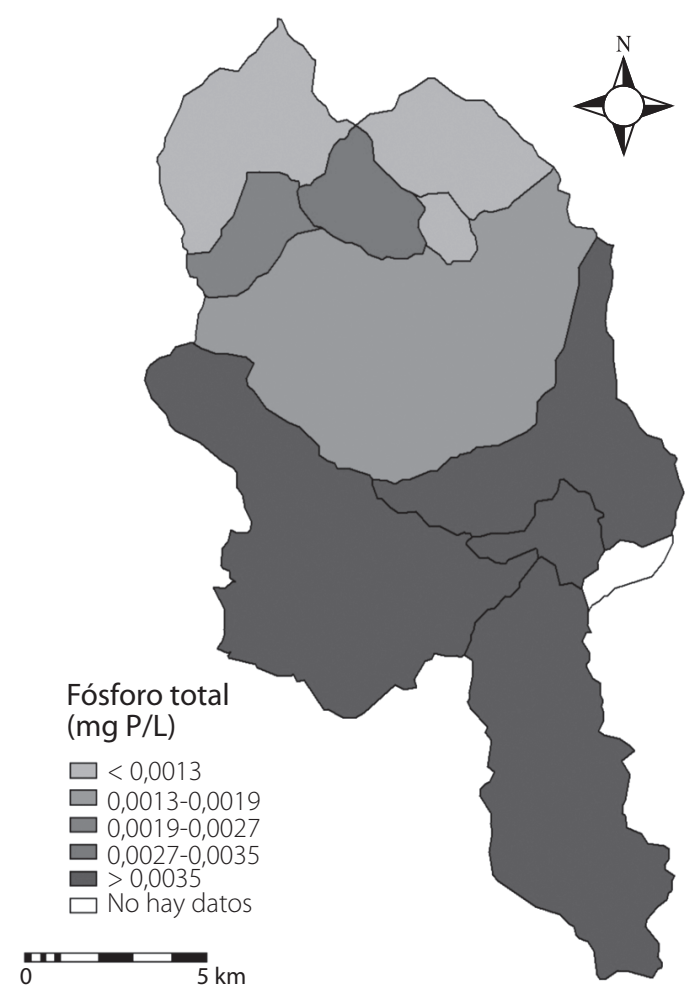

FIG. 22. Alcalinidad en las aguas superficiales de la cuenca del río Rincón en la Península de Osa.

\section{AGRADECIMIENTOS}

A la Vicerrectoría de Investigación de la Universidad de Costa Rica por el presupuesto asignado al proyecto No. 802-A6-104"Balance hídrico y Caracterización fisicoquímica de las aguas superficiales de la cuenca del Río Rincón en la Península de Osa, Puntarenas, Costa Rica".

\section{REFERENCIAS}

Alabaster, J. S. \& R. Lloyd. 1982. Water Quality Criteria for Freshwater Fish. Butterworths, Londres, Inglaterra.

Aminot, A. \& F. Andrieux. 1996. Concept and determination of exchangeable phosphate in aquatic sediments. Water Resource 30: 2805-2811.

ANZECC (Australian and New Zealand Environment Conservation Council). 2000. An introduction to the Australian and New Zealand guidelines for fresh and marine water quality. National Water Quality Management Strategy, Camberra, Australia.

Bailey, R.G. 1980. Description of the Ecoregions of the United States. Departamento de Agricultura de los Estados Unidos, Ogden, Utah, EEU.

Barrantes, J., A. Liao \& A. Rosales. 1985. Atlas Climatológico de Costa Rica. MAG-CORENA, San José , Costa Rica. 
Barrios, L., T. Quesada, C. Pérez, A. Alfaro, A. Calero, J. Torres, A. Cosillo, E. Aguirre, D. Rodríguez, O. Arias, Y. Fallas \& D. Ríos. 1988. Geología General de la Península de Osa, Costa Rica, Proyecto de Planificación del Parque Nacional Corcovado.

Bellos, D. \& T. Sawidis. 2005. Chemical pollution monitoring of the River Pinios (Thessalia-Greece). Journal Environmental Management 76: 282-292.

Benoit, D. A. \& Ch. E. Stephan. 1988. Ambient Aquatic Life Water Quality Criteria for Chloride. Agencia de Protección Ambiental de Estados Unidos, Duluth, Minnesota, EEUU.

Berránge, J.P. 1989. Origin of Gold from the Golfo Dulce Placer Province, Southern Costa Rica. Circum-Pacific Council for Energy and Mineral Resources, Earth Science Series 16: 299-304.

CCME (Canadian Council of Ministers of the Environment). 1999. Canadian Water Quality Guidelines for the Protection of Aquatic Life. Winnipeg, Canada.

CCME (Canadian Council of Ministers of the Environment). 2005. Canadian Water Quality Guidelines for the Protection of Aquatic Life: Phosphorus. Winnipeg, Canada.

Chapman, D. 1996. Water Quality Assessments - A Guide to Use of Biota, Sediments and Water in Environmental Monitoring. E \& FN Spon, Cambridge, Inglaterra.

Dai, M., X. Guo, W. Zhai, L. Yuan, B. Wang, L. Wang, P. Cai, T. Tang \& W. Cai. 2006. Oxygen depletion in the upper reach of the Pearl River estuary during a winter drought. Marine Chemistry 102: 159-169.

Denyer, P. \& S. Kussmaul. 2000. Geología de Costa Rica. Tecnológica, Cartago, Costa Rica.

Drever, J. L. 1988. The Geochemistry of Natural Waters: Surface and Groundwater Environments. Prentice-Hall, Englewood Cliffs, Nueva Jersey, EEUU.

Eaton, A., L. S. Clesceri, E. W. Rice, A. E. Greenberg \& M .A. Franson. 1998. Standard Methods for the Examination of Water and Wastewater. APHA, AWWA, WEF, Columbia, Washington, EEUU.

Guerrero, J. P., I. Pla-Sentís \& R. Camacho. 2004. Génesis de un suelo sódico alcalino en Chaguaramas, Venezuela. Agronomía Tropical 54: 433-460.

Hammen, C.S. 1976. Estuarine Processes: Uses, Stresses, and Adaptations to the Estuary. Academic, Nueva York, Nueva York, EEU.

Herrera, W. 1985. Vegetación y clima de Costa Rica. EUNED, San José, Costa Rica.

Holdridge, L.R. 1982. Ecología basada en zonas de vida. IICA, San José, Costa Rica.

Holmes, S. 1996. South African Water Quality Guidelines. Volume 7: Aquatic Ecosystems. Departamento de Asuntos Hídricos y Forestales, Pretoria, Gauteng, Sudáfrica.

Iqbal, M.Z., E.J. Brown \& M. E. Clayton. 2006. Distribution of phosphorus in a biologically restricted lake in lowa, USA. Journal Hydrology 326: 349 - 366.

Jonnalagada, S. B., G. Mhere. 2001. Water Quality of the Odzi River in the Eastern Highlands of Zimbabwe. Water Resource 35: 2371-2376.
Kowalkowski, T., Z. Radoslaw, S. Jacek \& B. Bogusław. 2006. Application of chemometrics in river water classification. Water Resource 40: 744 - 752.

Lopes, J.F., J. M. Dias, A. C. Cardoso \& C. I. V. Silva. 2005. The water quality of the Ria de Aveiro lagoon, Portugal: From the observations to the implementation of a numerical model. Marine Environmental Research 60: 594-628.

McNeely, R. N., V. P. Neimanis \& L. Dwyer. 1979. Water Quality Sourcebook: A guide to water quality parameters. Ottawa, Ottawa, Canada.

MINAE (Ministerio del Ambiente y Energía de Costa Rica) \& MINSA (Ministerio de Salud de Costa Rica). 2007. Decreto No. 33903-MINAE-S Reglamento para la Evaluación y Clasificación de la Calidad de Cuerpos de Agua Superficiales. San José, Costa Rica.

Ministerio del Ambiente. 2006. Water Quality: British Columbia Approved Water Quality Guidelines. Víctoria, Columbia Británica, Canadá.

Nagpal, N.K., D.A. Levy \& D.D. MacDonald. 2003. Ambient water quality guidelines for chloride. Víctoria, Columbia Británica, Canadá

Nordin, R. N. \& L. W. Pommen. 1986. Water Quality Criteria for Nitrogen (Nitrate, Nitrite and Ammonia). Víctoria, Columbia Británica, Canadá.

OMS (Organización Mundial de la Salud). 2006. Guidelines for drinking Water Quality. Ginebra, Suiza.

Osorio, A. \& R. Césped. 2002. Efecto de Métodos de riego localizado en la salinidad del perfil de suelo en Vid de Mesa: Conductividad Eléctrica, Sodio, Cloro y Boro en distintos puntos del perfil. Agricultura Técnica 60: 178-194.

Pérez, A.G. 2004. Evaluación de la Calidad de las Aguas de Drenaje del Sector de Riego de Tamarindo para el Manejo de Humedales en el parque Nacional Palo Verde. Tesis de Maestría, Universidad de Costa Rica, San José, Costa Rica.

Rosero, L., T. Maltodano \& R. Bonilla. 2002. Bosque y Población en la Península de Osa. Revista Biología Tropical 50: 585-598.

Stumm, W. \& J. J. Morgan. 1996. Aquatic Chemistry. Wiley, Nueva York, Nueva York, EEUU.

Thursby, G., D. Miller, S. Poucher, L. Coiro, W. Munns \& T. Gleason. 2000. Ambient Aquatic Life Water Quality Criteria for Dissolved Oxygen (Saltwater): Cape Cod to Cape Aterras. Agencia de Protección Ambiental de Estados Unidos, Columbia, Washington, EE UU.

Umaña, G. 1998. Characterization of some Golfo Dulce drainage basin rivers (Costa Rica). Revista Biologia Tropical 46: 125.

USEPA (Agencia de Protección Ambiental de Estados Unidos). 2006. National Recommended Water Quality Criteria. Columbia, Washington, EE UU.

Vargas, G. 1989. Evaluación ecológica de Impactos Ambientales en la Explotación de Oro: Casos del río Tigre y Agujas, Península de Osa, Costa Rica. Geoistmo 3: 81-93.

Williamson, D. 2002. Manitoba Water Quality Standards, Objetives and Guidelines. Winnipeg, Manitoba, Canadá. 